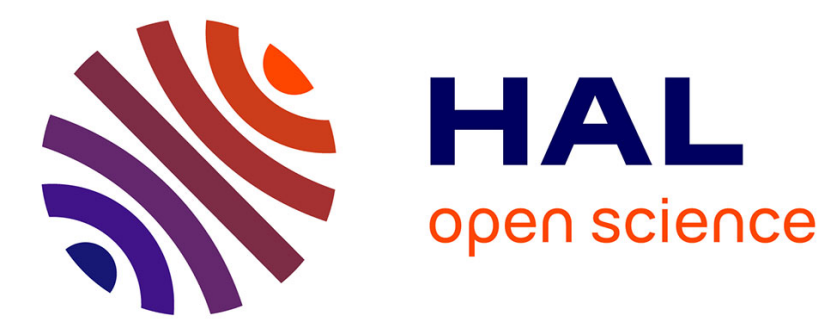

\title{
COCHLEATE DRUG DELIVERY SYSTEMS: AN APPROACH TO THEIR CHARACTERIZATION
}

\author{
Antonio Lipa-Castro, François-Xavier Legrand, Gillian Barratt
}

\section{To cite this version:}

Antonio Lipa-Castro, François-Xavier Legrand, Gillian Barratt. COCHLEATE DRUG DELIVERY SYSTEMS: AN APPROACH TO THEIR CHARACTERIZATION. 2021. hal-03285762

\section{HAL Id: hal-03285762 \\ https://hal.science/hal-03285762}

Preprint submitted on 13 Jul 2021

HAL is a multi-disciplinary open access archive for the deposit and dissemination of scientific research documents, whether they are published or not. The documents may come from teaching and research institutions in France or abroad, or from public or private research centers.
L'archive ouverte pluridisciplinaire HAL, est destinée au dépôt et à la diffusion de documents scientifiques de niveau recherche, publiés ou non, émanant des établissements d'enseignement et de recherche français ou étrangers, des laboratoires publics ou privés. 


\title{
COCHLEATE DRUG DELIVERY SYSTEMS: AN APPROACH TO THEIR CHARACTERIZATION
}

Antonio Lipa-Castro, François-Xavier Legrand and Gillian Barratt ${ }^{*}$

Université Paris-Saclay, CNRS, Institut Galien Paris-Saclay, 92290, Châtenay-Malabry, France.

* Corresponding author

\begin{abstract}
Cochleate systems formed from phospholipids have very useful properties as drug delivery systems with sustained release capabilities, which are able to improve bioavailability and efficacy, reduce toxicity and increase the shelf-life of encapsulated molecules. These nanometric or micrometric structures are usually obtained after interaction of negatively charged liposomes with a positively charged bridging agent. Many different methods are now available to prepare cochleates and there are also numerous techniques that can be used to characterize them, some of which can be easily applied while others require more sophisticated equipment or analysis. The present review describes the important features of this drug delivery system; including their structural properties and potential applications, as well as a brief account of methods for their preparation and an extensive description of the techniques used for their characterization. This information could guide formulators in their choice of methods of characterization that would be best suited to their needs in terms of time, precision and technological difficulty.
\end{abstract}

Keywords: cochleates, phospholipids, drug delivery, SAXS/WAXS, FT-IR, light scattering
Abbreviations
DLS: Dynamic light scattering
DOPS: Dioleoyl phosphatidylserine
DSC: Differential scanning calorimetry
EDTA: Ethylenediaminetetraacetic Acid Tetrasodium Salt
FT-IR: Fourier-transform infrared spectroscopy
MLV: Multilamellar vesicles
PA: Phosphatidic acid
PC: Phosphatidylcholine
PE: Phosphatidylethanolamine 
PG: Phosphatidylglycerol

PI: Phosphatidylinositol

POPS: Palmitoyl-oleoyl phosphatidylserine

PS: Phosphatidylserine

NMR: Nuclear magnetic resonance 


\section{INTRODUCTION}

Oral drug delivery is the most convenient route for drug administration and is preferred because of safety and good patient compliance (Agrawal et al., 2014). However, many useful drugs have poor oral bioavailability due to their very low water solubility or poor permeation through biological membranes. Over the last few years, drug delivery systems have become gaining importance as a means of promoting the modified release of active ingredients (Patra et al., 2018). They are used to improve the therapeutic index and reduce the side effects of drugs, by overcoming problems such as limited solubility, drug aggregation, chemical instability, low bioavailability, poor biodistribution and lack of selectivity. The most commonly described systems include micelles, liposomes, dendrimers, nanocapsules and nanospheres (Li et al., 2019; Sharma et al., 2016). Among these systems, lipid-based delivery systems have been reported to improve oral bioavailability of poorly water-soluble drugs (Kalepu et al., 2013). Due to their biocompatibility and the similarity of the lipid bilayer with the cell membrane, liposomes are the most widely employed systems at present, but they are limited by their poor stability, particularly by the oral route (Pawar et al., 2015). Another type of phospholipid-based structure, known as cochleates, could have some advantages over liposomes for the oral route ( $\mathrm{Li}$ et al., 2015). Cochleates, which were first described by Papahadjopoulos et al. in 1975, are stable phospholipid-cation precipitates (Zarif et al., 2000), formed of rolled-up negatively charged phospholipid bilayers bridged by multivalent cations (Pawar et al., 2015). Several methods to prepare this type of drug delivery system have been developed (Ramasamy et al., 2009). However, it is necessary to use a number of characterization techniques to determine the optimal composition for the cochleates and the limits to the amount of drug that can be incorporated, as well as to evaluate their stability over time. Therefore, a number of different techniques have been used to characterize cochleate systems. Methods such as dynamic light scattering (DLS), microscopy (Asprea et al., 2019), differential scanning calorimetry (DSC) (Sarig et al., 2011), infrared spectroscopy and X-ray diffraction have been used to study the morphology, size, surface charge and internal structure of the cochleates (Bozó et al., 2017). For a complete characterization of cochleates, and to distinguish them from other phospholipid-based drug delivery systems, it is necessary to combine a number of complementary techniques. In this context, it is important to understand what information can be obtained from each technique. In this review we outline the advantages of cochleates as drug delivery systems, present the different protocols of preparation and describe the different methods available for their characterization in detail. 


\section{COCHLEATES: PHYSICOCHEMICAL DESCRIPTION}

Cochleates are stable phospholipid-cation precipitates comprised of a tightly multilayered packed structure formed by a continuous, solid, lipid bilayer sheet rolled up in a spiral, with no internal aqueous space, as shown in Figure 1 (Nagarsekar et al., 2016; Santangelo et al., 2000). They are formed by the interaction of negatively charged liposomes with divalent cations (Syed et al., 2008) triggering a dehydration and self-assembly process followed by a spontaneous arrangement to form more complex systems with a typical cigar shape. Figure 2 illustrates this mechanism (Nagarsekar et al., 2016).

Although cochleates are usually described as cigar-shaped nanostructures, different morphologies have been observed depending on the type of phospholipid and bridging agent used. Hence, when dioleoyl phosphatidylserine (DOPS) was used homogenous cigar-shaped particles were obtained whereas planar and spherical sheets were obtained when palmitoyloleoyl phosphatidylserine (POPS) and soy PS were employed respectively (Landge et al., 2013). Furthermore, fibrils and spherical cochleates was observed when bridging agents other than divalent cations were used (Syed et al., 2008).

Depending on their physico-chemical properties, drugs can be incorporated either within the phospholipid bilayers or sandwiched between the bilayers (Harkare et al., 2013) (Figure 3). Thus, due to the special internal structure of the cochleates, they can protect the encapsulated material against harsh conditions and thereby provide a unique and efficient way of formulating drug molecules (Bozó et al., 2017).

\section{RAW MATERIALS}

3.1. Lipids: These are the main ingredients for obtaining the cochleates. The process usually begins with the preparation of negatively charged liposomes, for which the most commonly used phospholipid with a negative charge on the headgroup at physiological $\mathrm{pH}$ is phosphatidylserine (PS), and the synthetic dioleoylphosphatidylserine (DOPS) is frequently employed (Bozó et al., 2017; Nagarsekar et al., 2016; Syed et al., 2008). As shown in Figure 4, other negatively charged phospholipids, such as phosphatidic acid (PA), phosphatidyl glycerol (PG) and phosphatidylinositol (PI), have also been shown to form cochleates. In addition, mixtures of negatively phospholipids and other phospholipids (PS/PC where PS > 50\%) can also yield cochleates but require a higher concentration of bridging agents (Li et al., 2015). Mixtures containing at least $75 \%$ of PS, PI, PA, PG with PC, PE and other less abundant phospholipids have also been used 
(Sankar \& Reddy Y, 2010). It is not necessary to use synthetic phospholipids with defined acyl chains; cochleate structures can also obtained from naturally occurring phospholipids such as soy PS (Mannino et al., 2004) and soy PC (Asprea et al., 2019). This latter result is surprising because PC is zwitterionic with no net charge. However, the liposomes from which the soy PC cochleates were formed had a fairly high negative zeta potential so it is possible that the natural PC used contained other, charged, lipids that could be bridged by the $\mathrm{Ca}^{2+}$ ions (Asprea et al., 2019).

3.2. Bridging agent: The divalent cations maintain the rolled sheet structure by electrostatic interaction between their positive charge and that of the negatively charged lipid head groups in the bilayer (Koomer, 2009). Divalent cations such as $\mathrm{Ca}^{2+}, \mathrm{Mg}^{2+}, \mathrm{Ba}^{2+}$ and $\mathrm{Zn}^{2+}$ can all be used, but the calcium ion have been reported to be the most efficient (Landge et al., 2013). Cochleates bridged by calcium have smaller dimensions and a higher degree of dehydration than those formed with magnesium. Furthermore, calcium-based cochleates were found to be more tightly packed, highly ordered and required a much lower concentration of bridging ions (Flach \& Mendelsohn, 1993). Some researchers have reported the use of some biologically active molecules, such as tobramycin, polylysine and oligo-acyl-lysyls, as an alternative to metal cations as bridging agents for cochleates, thus combining encapsulation and cochleate stabilisation (Sarig et al., 2011; Syed et al., 2008).

3.3. Cholesterol: Despite not being essential for obtaining the cochleate structure, several cochleate formulations have included the sterol cholesterol (Asprea et al., 2019; Pham et al., 2013) that can influence it's structure, enhancing the dehydration and further immobility of the phospholipids without changing the stoichiometry of the binding agent and the phospholipid by altering the acyl chain packing (Choi et al., 1991).

3.4. Other components: Aggregation is a commonly described drawback of cochleates (Bozó et al., 2017). It has been shown that aggregation can be inhibited by changing the surface properties of the cochleates and thereby inhibiting cochleate-cochleate interaction. Therefore some aggregation inhibitors, such as casein, methylcellulose or albumin, may be included to maintain the cochleates as individual particles (Mannino et al., 2005). 
3.5. Encapsulated Drug: Many reports have described the successful encapsulation of vaccines, antibiotics, antifungals and other drugs in cochleates (Bozó et al., 2017) (Ramasamy et al., 2009), as shown in Table 1. The physicochemical properties of the drug will define its location in the cochleate structure, as shown in Figure 3. Thus hydrophobic, amphiphilic, negatively or positively charged drug can be incorporated and delivered by cochleates (Leila Zarif et al., 2000).

\section{ADVANTAGES OF COCHLEATES AS A DRUG DELIVERY SYSTEM}

Although cochleates were first described in 1975, it was not until twenty years later that they began be considered as a vehicle for drug delivery (Gould-Fogerite and Mannino, 1997; Jin et al, 2001). Since they are composed of natural materials, cochleates offer a biocompatible drug delivery system that is well tolerated without producing an immunogenic response (Ramasamy et al., 2009; Zarif, 2002). It has been shown that repeated oral and intraperitoneal dosing in mice was well tolerated, non-toxic and non-inflammatory (Gibson et al., 2004; Zarif \& Mannino, 2002). Their ability to provide controlled release of drugs in vitro (Asprea et al., 2019, Pham et al., 2014) and in vivo (Miclea et al., 2007, Santangelo et al., 2000; L. Zarif et al., 2000) has been demonstrated.

The properties of a drug delivery system do not depend solely on the components (such as the type of lipid) but also the way in which they are organized in the structure. Thus, the dehydrated, tightly packed nature of cochleates creates a stable structure (Landge et al., 2013) that can have advantages for the encapsulation and retention of drugs when compared with liposomes, although the basic phospholipid components of the two systems are very similar. Drugs can be easily inserted into or between the PS bilayers where they are protected against harsh condition such as gastrointestinal media (Pham et al., 2014), and proteolytic enzymes (Koomer, 2009; Rao et al., 2007). Furthermore, the multilamellar structure can provide a slow release profile for the drug (Rao et al., 2007). Finally, due to their dehydrated structure, cochleates are less susceptible to oxidation of both the phospholipids and the encapsulated drug than liposomes and, in contrast to vesicular systems, they retain their structure after freeze-drying without any cryoprotectant being necessary, thus greatly increasing their shelf life (Pham et al., 2014).

In particular, cochleates can improve the oral bioavailability of hydrophilic and hydrophobic drugs (Aigner and Lass-Flörl, 2020; Bhosale et al., 2013; Harkare et al., 2013; Vijeta et al, 2011). As illustrated in Figure 5, the high tension at the bilayer edges of the cochleates when they interact with the membrane of intestinal cells is suggested to be the driving force for 
fusion with these membranes, thereby enhancing the absorption of the encapsulated drug (Syed et al., 2008). In addition, as particulate material, cochleates may be captured by M cells in Peyer's patches and translocated across the epithelial barrier in this way. Cochleates that reach the circulation intact could be taken up by macrophages and delivered to sites of infection, for example, in the case of amphotericin B-loaded cochleates (Rongen, 2016). However, within cells, in response to the low calcium levels in the cytoplasm, the cochleate structure could be destabilized and release the loaded drug. Since direct contact between the drug and the intestinal cells is avoided, toxic effects may be avoided.

Despite these advantages, no cochleate-based drug delivery formulation is on the market yet. A phase II trial with amphotericin B-loaded cochleates administered by the oral route was recently conducted with patients suffering from Candida infections, as described by Aigner and Lass-Flörl (2020). No significant toxicity was recorded, but the outcomes were not superior to those obtained with the reference drug, fluconazole. A better knowledge of the mechanisms involved in cochleate interaction with the gastrointestinal tract would help to optimize their use, but research is hampered by the quite complicated methods of preparation and the difficulty in characterizing the systems produced, as well as the cost of the starting material when phospholipids of synthetic origin are used. The information below could contribute to orientating the choice of methods and further developing these interesting drug delivery systems.

\section{METHODS FOR COCHLEATE PREPARATION}

Cochleate preparation is generally based on the interaction of negatively charged liposomes with a positively charged cation, which generates fusion, dehydration and precipitation of larger structures corresponding to cochleates. The methods of preparing cochleates differ in the dispersing medium used and in the way in which the bridging agent is incorporated. Depending on these parameters, cochleates of different sizes can be obtained in the nanometric or micrometric range.

\subsection{Trapping method}

This is a simple method that involves the mixing of an aqueous lipid suspension (liposomes, micelles, etc) with a bridging agent. However, it rarely yields a narrow size distribution of the particles (Mannino et al., 2005; Zarif \& Mannino, 2002). Modifications to improve the entrapment efficiency based on the use of solvents such as dimethylsulfoxide, ethanol, acetonitrile have been evaluated, allowing a wider range of molecules to be incorporated into 
the cochleates and also permitting the optimal lipid:molecule ratio to be determined without excessive experimentation (Mannino et al., 2005).

\subsection{Hydrogel Method}

This method, the most frequently used, allows small-sized cochleates to be formed from unilamellar liposomes. The liposomes are suspended in an aqueous two-phase medium formed by immiscible polymer solutions. Firstly, liposomes are added to polymer A (dextran, polyethylene glycol, etc.), after which the dispersion is suspended in polymer B (polyvinylpyrrolidone, polyvinylalcohol, Ficoll ${ }^{\mathrm{TM}}$, polyvinyl methyl ether, polyethylene glycol, etc.). A two-phase aqueous system is formed, with the liposomes dispersed in small droplets of polymer A. The bridging agent is then added to the system, forming a cochleate precipitate with a particle size of less than one micron. The precipitate must then be washed to remove the polymers (Jin et al., 2001; Zarif et al., 2003).

\subsection{Dialysis method}

Two methods employing dialysis have been described. In the first (liposomes before cochleates (LC) method), liposomes are formed by dialyzing the detergent from a solution containing lipid and the material to be encapsulated. These vesicles are then subjected to a second dialysis step in presence of the bridging agent (Gould-Fogerite \& Mannino, 1997).

In the second method, called the direct calcium (DC) dialysis method, the mixture of lipid and detergent is directly dialyzed against buffer containing the bridging agent. It has been reported that drug encapsulation is lower than with the LC method (Gould-Fogerite \& Mannino, 1997). and unlike the LC method, the DC dialysis method forms large cochleates (Harkare et al., 2013). The detergent used can be ionic such as cholate salts, deoxycholate salts and similar, or nonionic such as Tween, Brig or Triton. The most suitable nonionic detergents are those containing sugar head groups such as the alkyl glucosides, preferably $n$-octyl- $\beta$-Dglucopyranoside (Gould-Fogerite \& Mannino, 1997).

\subsection{Emulsification-lyophilization method}

This method involves an emulsification-lyophilisation procedure in which the lipid is dissolved in the oil phase $(\mathrm{O})$, one aqueous phase containing the bridging agent and a cryoprotectant in water (W1) and a buffer as the outer water phase (W2). After preparation of a W1/O/W2 emulsion, a lyophilisation procedure is carried out and nano-sized cochleates are obtained on rehydration of the lyophilized powder (Wang et al., 2014). 


\subsection{Microfluidic method}

This method avoids elaborate preparation procedures and provides a monodispersed spherical system (3-5 $\mu \mathrm{m}$ in diameter) that retains a typical cochleate structure. The lipid is dissolved in ethanol and the bridging agent is dissolved in aqueous buffer. Mixing of the two phases is controlled by a microfluidic device with herringbone channels and the resulting suspension is collected. The morphology of the cochleates is strongly influenced by the flow rate of mixing and the lipid concentration. Thus, while at lower speeds aggregate structures are formed, at higher speeds spherical and regular particles are obtained. On the other hand, lower lipid concentrations can give extremely uniform structures, as shown in Figure 6. In comparison with conventional techniques, this approach is rapid and easy to handle (Nagarsekar et al., 2017).

\subsection{Solvent injection method}

Unlike the methods mentioned above that use phospholipids as the basis for cochleates, this approach employs cholesterol dispersed in organic solvent injected quickly into a water phase at a controlled temperature between $40^{\circ} \mathrm{C}$ and $75^{\circ} \mathrm{C}$. An aqueous cholesterol microcrystal suspension is obtained. Electron microscopy revealed a hollow, cylindrical, tightly-coiled, multi-bilayer form of cholesterol that resembles classical cochleate cylinders (Harris et al., 2011). 


\section{CHARACTERIZATION TECHNIQUES FOR COCHLEATES}

The formulation of cochleates remains a challenge and a wide range of characterization techniques are necessary to evaluate the objects that are produced and optimize the procedures. Based on their typical morphology, different states of aggregation and their particular internal structure, among other features, cochleates can be characterized by many methods. In the sections below, we review the different methods that can be used to characterize cochleate systems and the information that can be obtained from each of them. Table 2 provides a summary of these remarks.

\subsection{MORPHOLOGY, SIZE AND POLYDISPERSITY}

Size and shape are two of the most important parameters for colloidal dispersions. Cochleates are described as having a typical cigar shape and are therefore anisotropic, which renders them more difficult to characterize than spherical particles; for example, by light scattering methods where the algorithms assume spherical objects. It is also important to determine their polydispersity and degree of agglomeration that must be controlled if they are to be used as drug delivery systems.

\subsubsection{Light Scattering Techniques}

Dynamic light scattering (DLS) is a widely employed technique for the measurement of size and polydispersity distribution (Asprea et al., 2019) that is often applied to colloidal suspensions in the nanometric or low micrometric ranges. This technique analyses fluctuations of scattering of laser light to determine the Brownian movement of the particles and hence their average hydrodynamic diameter. A single-frequency laser is directed towards the sample dispersed in liquid in a cuvette. The incident laser light is scattered in all directions and detected at one or more angles over time and the fluctuations in intensity are used to determine the diffusion coefficient and the particle size by the Stokes-Einstein equation (Equation 1). Commercial instruments that are simple to use with a minimum of sample preparation are available. In contrast to microscopic techniques, the results of DLS measure a mean parameter over the whole population rather than individual particles, although the data processing algorithms are able to detect a mixture of two or three distinct populations. A more serious limitation for cochleates is that the algorithms usually assume that the particles are spherical. This can lead to errors in the mean diameter of cigar-shaped particles. Nevertheless, the quick, easy and precise operation of the technique and the sensitivity to large particles (allowing it to detect aggregation) means that it is a useful standard procedure for cochleates 
(Mourdikoudis et al., 2018), especially when combined with a microscopic technique as described below.

$$
\mathrm{D}=K b T /\left(6 \pi \eta R_{H}\right)(\text { Equation 1) }
$$

D: Translational diffusion coefficient; Kb: Boltzmann constant; T: Temperature; $\eta$ : Viscosity; $\mathrm{R}_{\mathrm{H}}$ : Hydrodynamic radius

A variant of the DLS technique is nanoparticle tracking analysis (NTA) in which the individual Brownian movement of a number of nanoparticles is followed by laser light scattering and a distribution of particle size and concentration is obtained. The results differ from traditional DLS because they represent individual nanoparticles rather than an average result and therefore it is easier to distinguish separate populations in polydisperse samples (Filipe et al., 2010). However, the algorithms used to relate diffusion constants to diameter still assume that the particles are spherical, so the relevance for anisotropic cochleate particles remains limited.

\subsubsection{Microscopic Techniques}

Optical microscopy has been used as an straightforward method for characterization of cochleates in several studies (Bozó et al., 2017; Syed et al., 2008; L. Zarif et al., 2000). It is very useful when evaluating cochleates of large size, for observing the cylindrical form of the particles and also for detecting the presence of agglomerations, a very common drawback in the manufacture of cochleates but is limited to large cochleates or aggregates. In fact, the resolution of the technique means that cochleates cannot be observed in detail and nano-sized cochleates cannot be resolved at all. Therefore, more advanced microscopic characterization techniques have been brought into play to improve the structural characterization of cochleates and elucidate the mechanisms of their formation. These include atomic force microscopy (Bozó et al., 2017), transmission electron microscopy (Asprea et al., 2019), scanning electron microscopy and freeze-fracture electron microscopy (Nagarsekar et al., 2016). Amongst these, freeze-fracture electron microscopy is considered to be the most appropriate technique to evaluate the morphology of cochleates because it allows the rolled structure and the closely apposed bilayers to be visualized (Papahadjopoulos-Sternberg, 2012; Zarif, 2005). A disadvantage is that sophisticated equipment and experienced operators are required. Therefore, it is preferable to use both optical and electron microscope to get a full view of the cochleate sample.

These microscopic techniques can also be used to determine the size and polydispersity of cochleates but this requires the observation of a sufficiently large number of particles (Zarif $\&$ 
Mannino, 2002), Nagarsekar et al., 2016). It also has to be remembered that sample preparation may modify the size of the cochleates. Image analysis software can help to collect data from a larger number of particles, but this requires that the particles are well separated one from another to avoid artefacts due to aggregates. Atomic force microscopy, which has a better resolution than optical microscopy, can provide a series of well-resolved snapshots that can be used to calculate the precise aspect ratio (length to diameter ratio) (Gao et al., 2019). Fluorescence microscopy has also been used to determine the particle size and shape of large cochleates after incorporation of a fluorescent probe into the bilayer. Thus, Miclea et al., included rhodamine-labelled dioleoylphosphatidylethanolamine in cochleates and measured their size on images obtained from fluorescent microscopy (Miclea et al., 2007). The formation of cochleates from proteoliposomes derived from bacteria was revealed by the binding of Texas Red-labelled albumin to their surface (Acevedo et al., 2012). Thus, monitoring by fluorescent microscopy has also been useful in the evaluation of cochleates in the retention of their morphology under external influences such as an ion-complexing substance (EDTA) (Mannino, 2016) and sonication (Acevedo et al., 2012).

Figure 7 shows examples of cochleate systems observed by different electron microscopic techniques.

\subsection{VESICLE FUSION AND AGGREGATION STATE}

\subsubsection{Turbidity}

Turbidity is a form of light scattering. While scattering is usually detected at an angle $\theta$ to the incident wave, turbidity it is detected by the reduction in the transmitted light at $\theta=0^{\circ}$. Thus, turbidity can be used to monitor the evolution of particle size or shape through changes in the light scattering properties or the optical density of vesicle suspensions (Beugin et al., 1995; Rachkauskas, 2014; Zerkoune et al., 2016). So, these techniques had been used to follow the fusion of liposomes into cochleates on the addition of divalent cations (Düzgüneş \& Ohki, 1977; Portis et al., 1979; Wilschut et al., 1980). This technique, which is easy to perform with an UV spectrophotometer, is able to distinguish the fusion of vesicles and reversible agglomeration (Nir et al., 1983) and so follow the stability of cochleates.

\subsubsection{Zeta potential}

Zeta potential, also called electrokinetic potential, is a physical property that is exhibited by any particle in suspension. It can be defined as the electrical potential at the slipping/shear 
plane of a colloid particle moving under an electric field (Bhattacharjee, 2016). This technique is useful to investigate the stability of cochleates in the environment because variation of zeta potential can indicate whether the physicochemical properties of the cochleates are altered. Thus Asprea et al. (2019) and Pham et al. (2014) used zeta potential measurements to monitor the stability of cochleates over time and after lyophilisation process. In addition, on the principle that the formation of cochleates occurs after the incorporation of a positively charged agent on negatively charged liposomes, zeta potential is very useful as it can distinguish the different states of aggregation that the systems pass through before reaching the final product (cochleates). Typically, the final product will present more positive potential zeta values than the precursor system (Pham et al., 2014).

\subsubsection{Fluorescence Spectroscopy}

Fluorescence spectroscopy can be used to probe the state of the lipid membrane and in this way confirm the cochleate structure. In this respect, laurdan (6-dodecanoyl- $N, N$-dimethyl-2naphthylamine) is often employed because of the sensitivity of its fluorescence properties to the surrounding environment (Parasassi et al., 1991). As shown in Figure 9, due to its localization at the interface between the polar head group and the acyl chains of phospholipids, the emission and excitation spectra of laurdan undergo a red shift, to higher wavelengths, on the transition of the bilayer from a gel phase to a liquid crystalline phase and, furthermore, the extent of this shift, due to dipolar relaxation, is influenced by the presence of water molecules (Ramani \& Balasubramanian, 2003). Thus, monitoring changes in laurdan fluorescence has been proposed as a method to detect the formation of cochleates (Miclea et al., 2007). These authors observed that the fluorescence spectrum of laurdan in liposomes prepared from brain phosphatidylserine showed a maximum of fluorescence emission at around $430 \mathrm{~nm}$, a typical laurdan profile for liposomes in the gel phase. A second peak at 490 $\mathrm{nm}$ was also obtained when the temperature was raised. This peak at $490 \mathrm{~nm}$ was reduced in intensity when cations were added, and a blue shift was observed for the peak at $430 \mathrm{~nm}$, suggesting dehydration between the bilayers, as would be expected when the cochleate state is obtained (Miclea et al., 2007). Thus this technique has been very useful to evaluate the impact of the inclusion of different drugs such as the blood-clotting protein factor VIII (Miclea et al., 2007) and an anti-microbial peptide (Livne et al., 2010) in the cochleate structure, and also to study different phosphatidylcholine/phosphatidylserine molar ratios and the effect of ionic strength (Ramani \& Balasubramanian, 2003). 
Another fluorescence-based technique, contents mixing, was used by Wilschut et al. (1980) to study vesicle fusion in the presence of calcium. In this case, two populations of liposomes were prepared, one containing a citrate chelate of terbium and the other dipicolinic acid (DPA). If the vesicles fuse and their contents mix, the resulting terbium/DPA complex is fluorescent. Using this technique, they were able to determine the threshold calcium concentration that would trigger fusion. 


\subsubsection{Differential scanning calorimetry}

Differential scanning calorimetric (DSC) measures heat flow in a sample when it is exposed to a gradual controlled temperature change. This technique is frequently used to characterize phospholipid-based systems because pure phospholipids demonstrate a clear phase transition from a solid to a liquid state of the acyl chains at a specific temperature, known as the transition temperature. Modifications of this temperature and the heat flow during the transition can give information about drug-lipid interaction, the state of the lipid and melting and recrystallization behaviour in the drug delivery system (Chiu \& Prenner, 2011).

In this way, the formation of cochleate structures after addition of divalent cations to bovine brain PS vesicles was accompanied by an increase in the transition temperature to an extremely high value, indicating highly ordered crystalline acyl chains, although this naturally occurring phospholipid contains a mixture of different chains (Portis et al., 1979). Silvius and Gagne (1984) studied the phase transitions of different mixtures of single molecular species of phosphatidylserine and phosphatidylcholine in the presence and absence of calcium and used the results to produce phase diagrams. Although the two phospholipids were miscible in the absence of calcium, when the divalent cation was present, some phase separation was observed, corresponding to cochleate systems containing a high proportion of PS. This allowed them to define the proportions of lipids that could be used to form cochleates. This sort of study was also applied to cochleates constructed using cationic glycopeptides as bridging agents, with or without the antibiotic erythromycin (Sarig et al., 2011).

DSC can also be used to probe interactions between the cochleate system and an encapsulated drug. The absence of a melting peak characteristic of the drug when it is contained in cochleates is often observed, demonstrating the interaction of the drug with the phospholipid bilayer (Landge et al., 2013).

\subsection{INTERNAL STRUCTURE}

\subsubsection{X-ray diffraction}

X-ray diffraction gives information on a molecular scale about lipid bilayer structure. X-ray scattering/diffraction experiments are usually divided into experiments at small angles (SAXS/D) and at wide angles (WAXS/D). Both techniques as based on the same physical principles because they observe the coherent scattering from a sample as a function of the electron distribution in the sample. The distinction is that SAXS has diffraction $2 \theta$ in the range from $0.03^{\circ}$ up to roughly $9^{\circ}$, while WAXS has a diffraction $2 \theta$ angle range of $9-100^{\circ}$. 
SAXS gives information about structures with dimensions between 10 and $1000 \AA$ (1-100 $\mathrm{nm})$ whereas WAXS normally reports distances in the range of $1-10 \AA(<1 \mathrm{~nm})(\mathrm{He}, 2018)$. Bragg's law (Equation 2) is used to relate peaks in the X-ray diffraction pattern to real repeat spacing:

$$
n \lambda=2 d \sin \theta \text { (Equation 2) }
$$

where $n$ is an integer corresponding to the order of reflection, $\lambda$ is the wavelength of the X-ray being used, $d$ is the structural repeat distance (McCarthy \& Brooks, 2016).

Therefore, X-ray diffraction is a useful technique for studying the internal structure of cochleates and how this can be affected by encapsulated drug. In particular, it is possible to distinguish between the tightly packed bilayers of cochleates and the more distanced bilayers of multilamellar vesicles (MLV) (Hui et al., 1983). More precisely, SAXS can reveal the changes in correlation and ordering of phospholipid bilayers (Bozó et al., 2017) while WAXS can explore the acyl chain packing (Gao et al., 2019; Hui et al., 1983). The SAXS pattern of cochleates can be measured for scattering vector values comprised between 0.03 and $0.6 \AA^{-1}$ corresponding to the range of bilayer thickness and periodicity (Bozó et al., 2017) whereas WAXS patterns are measured for scattering vector values greater than $1.0 \AA^{-1}$ (Gao et al., 2019). SAXS studies of cochleates normally reveal a highly ordered lamellar structure with a Bragg diffraction peak repeat unit spacing of first, second and third order, multiple reflections from which the repeat distance of the cochleate bilayers can be calculated from the different order reflections; in particular the first reflection that shows the highest intensity (Bozó et al., 2017; Nagarsekar et al., 2017).

Thus, in Figure 10, a hydrated system in the absence of divalent cations, which would be expected to form MLVs, shows a very broad signal typical of an entirely uncorrelated multilamellar system. The addition of $\mathrm{Ca}^{2+}$ causes a change in the layer organization, showing sharp and equidistant Bragg reflection (Bozó et al., 2017). Hence SAXS can be employed to determine the proportion of negative lipid necessary to obtain the cochleate structure in combination with other components (Hui et al., 1983). Furthermore, X-ray diffraction may be used as an alternative approach for further characterization and to understand the distinguishing characteristics of the intermediate structures based on the gradual reduction of the repeat distances in the process of transforming multilamellar vesicles to cochleates by addition of a bridging agent (Nagarsekar et al., 2016).

Electron density profiles from SAXS patterns can be obtained after mathematical treatment and give a very precise view of the bilayer arrangement with or without an active molecule (Nagle and Wiener, 1989). In some case, they can provide an idea of the position of the 
molecule in the bilayer (Chemin et al., 2009). In the case of DOPS cochleates, for example, the addition of $5 \mathrm{~mol} \%$ of amphotericin $\mathrm{B}$ does not induce structural modifications and the electron density difference between amphotericin B and DOPS is too small to induce significant differences between the two electron density profiles (Figure 11, Lipa, Bourgaux, Legrand, Barratt, unpublished results).

\subsubsection{Fourier transform infrared (FT-IR) spectroscopy}

The structural organization of phospholipids can also be probed by FT-IR spectroscopy. This technique can detect ion-induced perturbations at particular phospholipid sites directly without the extensive sample modifications required for other techniques. FT-IR data can also provide useful structural correlations of phase behaviour that has been deduced from experiments (such as DSC) that do not yield direct information about molecular structure. In this way it is possible to identify a particular phase of phospholipid organization and to study the interaction of the bridging agent with the phospholipid headgroups (Bozó et al., 2017). In Figure 11, the complete FT-IR spectra of dimyristoylphosphatidylserine (DMPS) showing the phospholipid molecule and its characteristic vibrational bands is the following regions: The symmetric stretching vibration of the methylene band $\left(v_{\mathrm{s}} \mathrm{CH} 2\right)$ at 2850 to $2855 \mathrm{~cm}^{-1}$, ester carbonyl stretch $\left(v_{\mathrm{s}} \mathrm{C}=\mathrm{O}\right)$ at 1685 to $1780 \mathrm{~cm}^{-1}, \mathrm{NH}_{3}{ }^{+}$antisymmetric bending $\left(\nu_{\mathrm{as}} \mathrm{NH}_{3}{ }^{+}\right)$at 1620 to $1600 \mathrm{~cm}^{-1}$, carboxylate antisymmetric stretching band $\left(v_{\mathrm{as}} \mathrm{COO}^{-}\right)$at 1640 to 1620 $\mathrm{cm}^{-1}$ and the asymmetric stretching vibration of the phosphate moiety $\left(\mathrm{v}_{\mathrm{as}} \mathrm{PO}_{2}{ }^{-}\right)$from 1250 to $1220 \mathrm{~cm}^{-1}$ (Manrique-Moreno et al., 2016).

In this respect, PS-ion interactions during cochleate formation have been reported by several groups (Flach \& Mendelsohn, 1993). The information obtained from FT-IR studies of cochleate formation focuses on the stretching vibrations of three regions of phospholipid structure:

Acyl Chain Region: Flach and Mendelsohn (1993) observed an increase in frequency of about $8 \mathrm{~cm}^{-1}$ in the methyl symmetric bending mode near $1386 \mathrm{~cm}^{-1}$, the so-called "methyl umbrella" when calcium was added to dimyristoylphosphatidylserine bilayer to form cochleates. This modification had not previously been observed in phospholipid phase changes, for example the transition from the gel to the liquid crystal phase, and can therefore be considered as an indication of the formation of tightly packed bilayers in cochleates that modifies the environment of these methyl groups. These changes in the FT-IR correlate with a 
reduction in the lamellar repeat distance observed by X-ray diffraction (Flach \& Mendelsohn, 1993).

Shifts in both the asymmetric and symmetric methylene stretching modes of the acyl chain methylene groups at 2925 and $2854 \mathrm{~cm}^{-1}$ respectively to about 3-4 $\mathrm{cm}^{-1}$ lower when calcium ions were added to dioleoylphosphatidylserine (Choi et al., 1991). This lower frequency indicates an increase in the order of the chains induced by $\mathrm{Ca}^{2+}$ binding to the head groups. Interestingly, the addition of cholesterol to the complex causes the bands to be upshifted by 1 $\mathrm{cm}^{-1}$ and the asymmetrical stretching band to become wider, indicating the influence of cholesterol on acyl chain packing. A tighter lipid packing attributed to the strong interaction of $\mathrm{Ca}^{2+}$ with lipid head groups was also observed by Bozó et al. (2017). These authors also noted that these changes were reversed when the cochleate structure was destroyed by the addition of EDTA or citrate anions.

Carbonyl interfacial region: The ester carbonyl groups of the phospholipid also show modifications in the FT-IR spectrum when cochleates are formed. The Infrared spectrum of DOPS displays bands corresponding to two asymmetric carbonyl stretching vibrations at 1742 and $1727 \mathrm{~cm}^{-1}$ arising from these groups, as observed by Choi et al. (1991). In a similar study from another laboratory, bands at $1736 \mathrm{~cm}^{-1}$ and at $1725 \mathrm{~cm}^{-1}$ were reported (Bozó et al., 2017). After addition of $\mathrm{Ca}^{+2}$, four bands are generated that can be attributed to carbonyl groups with different degrees of hydration. The band with the lowest wave number at 1704 $\mathrm{cm}^{-1}$ has been assigned to one of the $\mathrm{C}=\mathrm{O}$ groups forming hydrogen bonds molecules of water (Choi et al., 1991), and the bands are also reduced in width, probably reflecting a large reduction in motional freedom as a result of complexation of the polar headgroups by $\mathrm{Ca}^{2+}$ (Bozó et al., 2017). The spectrum is also modified when cholesterol is added to the system, with narrowing of the bands (Bozó et al., 2017). Differences in the spectra recorded at $24^{\circ} \mathrm{C}$ and $41^{\circ} \mathrm{C}$ were also observed.

Polar Group Region: The interaction between divalent cations and the phospholipid that leads to cochleate formation occurs at the level of the polar head group. Therefore, the FT-IR spectra in this region are extremely informative. The dehydration or hydration state of the phosphate can be identified through a characteristic increase in the asymmetric $\mathrm{PO}_{2}{ }^{-}$ stretching frequency in the band region from 1221 to $1238 \mathrm{~cm}^{-1}$ (Flach \& Mendelsohn, 1993). Infrared spectra of phosphate group vibrations show a band at $1223 \mathrm{~cm}^{-1}$ that can be assigned to an asymmetric $\mathrm{PO}_{2}^{-}$stretching mode and three peaks at 1090, 1067, and $1043 \mathrm{~cm}^{-1}$ related to the symmetric $\mathrm{PO}_{2}^{-}$mode in fully hydrated DOPS. Upon $\mathrm{Ca}^{2+}$ binding asymmetric $\mathrm{PO}_{2}^{-}$ shows a narrower band at $1238 \mathrm{~cm}^{-1}$ indicating that $\mathrm{Ca}^{2+}$ binds, dehydrates and immobilizes 
the phosphate ester group. In addition, the symmetric $\mathrm{PO}_{2}^{-}$mode after addition of $\mathrm{Ca}^{2+}$ shows four bands at $1111,1102,1074$, and $1063 \mathrm{~cm}^{-1}$ that can be attributed to the torsion angles of the two P-O ester bonds (Choi et al., 1991).

Infrared spectroscopy has also been employed to probe the interactions between active molecules and lipids within the cochleate structure. Thus, Landge et al. (2013) saw changes in the FT-IR spectrum of ketoconazole when it was incorporated into cochleates, and also some changes in the peaks corresponding to DOPS.

\subsubsection{Nuclear magnetic resonance}

Nuclear magnetic resonance (NMR) is another technique that is able to provide information about the environment of the molecules within phospholipid assemblies and the changes that can occur when divalent cations are added. ${ }^{31} \mathrm{P}$ in the head group and ${ }^{2} \mathrm{H}$ (deuterium) in different parts of the molecule are the isotopes that are most often monitored. Thus, Tilcock et al. (1984) used both ${ }^{31} \mathrm{P}$ NMR and deuterium NMR with phospholipids labelled in the acyl chain. They investigated the effect of adding calcium ions to mixed systems of phosphatidylserine with phosphatidylcholine or phosphatidylethanolamine. In some cases, cholesterol was also added. When DOPS was mixed in equimolar proportions to DOPC or DOPE the ${ }^{31} \mathrm{P}$ NMR signal is modified progressively as the proportion of $\mathrm{Ca}^{2+}$ is increased, and the signal intensity decreases. This is interpreted as the segregation of DOPS into condensed cochleate cylinders, which was confirmed by freeze-fracture electron microscopy and small-angle X-ray diffraction. A difference was seen between DOPS and DLPS with more unsaturated acyl chains in the former that led to less condensed structures. When cholesterol was added to the DOPS/DOPE system (1:1:1 proportions) there was no phase separation but calcium converted the system to a hexagonal lattice. A DOPS/DOPC bilayer was also studied with and without cholesterol. In this case, no segregation was seen but the signal intensity again decreases with increasing calcium concentration. The results with phosphorous NMR were confirmed using DOPS with deuterium-labelled oleic acid (Tilcock et al., 1984).

Roux and Bloom (1990) studied the binding of different metal cations to bilayers of POPC and POPS in different proportions using deuterium NMR. In this work, the deuterium atoms were on the polar headgroup of the phospholipid. The quadrupolar splitting of both phospholipids was strongly affected by the presence of calcium. The modification in the NMR spectrum of POPS was correlated with $\mathrm{Ca}^{2+}$ binding measured using a radioactive isotope. This binding seemed to occur in two steps. Similar results were obtained with $\mathrm{Mg}^{2+}$, 
while monovalent cations $\left(\mathrm{Na}^{+}, \mathrm{K}^{+}\right)$were less deeply inserted into the membrane. In a followup paper (Roux and Bloom 1991), pure POPS membranes were also examined. The results give fundamental information about membrane fusion, including cochleate formation.

\subsection{INTERACTION WITH BIOLOGICAL SYSTEMS}

Since cochleates have been proposed as drug delivery systems for various types of molecules, it is important to study their interactions with cells. To do this, a fluorescent lipid can be incorporated into the cochleate membrane. Gibson et al. (2004) proposed cochleates as gene delivery vehicles and to investigate their interaction with phagocytic cells (macrophages) the cochleates were prepared with a rhodamine-containing lipid. To follow the cargo within the cochleates, a gene coding for green fluorescent protein was incorporated. Uptake by the 4T1 mouse breast cancer and H36.12 mouse macrophage cell lines and primary cultures of monocyte-derived mouse macrophages was detected by fluorescence microscopy. Similarly, cochleates bridged with drug molecules were labelled with fluorescent phosphatidylserine to study their interaction with bacteria and to compare this with liposomes made from the same materials (Syed et al., 2008). Asprea et al. (2019) encapsulated fluorescein isothiocyanate into cochleates to follow their uptake by the mouse macrophage-like cell line J774a.1 by confocal microscopy. Both cochleates and liposomes were taken up rapidly, with a similar location in the cytoplasm.

\subsection{OTHER STUDIES RELATED TO COCHLEATES}

Since cochleates have been postulated as a drug delivery system for the oral route, it is also necessary to understand their fate in gastrointestinal conditions. Thus, Asprea et al. (2019) tested the stability of a natural product, andrographolide, in cochleates after incubation in synthetic gastric fluid ( $\mathrm{pH}$ 1.8) and synthetic intestinal fluid ( $\mathrm{pH}$ 7.0). In this study, in both media the stability of the encapsulated drug (sensitive to the gastrointestinal environment) was evaluated demonstrating that encapsulation in the cochleates significantly improves their stability, as well as showing the stability of the cochleate particles themselves with respect to maintaining their size and shape during the incubation. In addition, a drug release profile shows non-significant liberation serving to demonstrate the retention of the drug in cochleate structure. However, a similar study was performed by Pham et al. (2014) with cochleates containing two anti-parasitic drugs: amphotericin B and miltefosine. In this proposed formulation, as well as demonstrating some alteration of the size and morphology of the 
nanoparticle after incubation, drug release was shown to occur preferentially in intestinal medium, driven by presence of bile salts.

\section{CONCLUSIONS}

Cochleates appear to be a promising drug delivery system that could improve the bioavailability of many drugs and protect them from harsh conditions. Many techniques have been used to characterize these particles and at the same time to optimize the formulation. Among these techniques, electron microscopy and X-ray diffraction are the preferred methods for exact identification and characterization. In addition, complementary studies using simpler methods for an easier or less expensive characterization such as optical microscopy, infrared spectroscopy, laurdan fluorescence, differential calorimetric scanning and others can be used. Future work on the formulation of cochleates will certainly produce alternative manufacturing technology as well as new methods for better characterization and optimization.

\section{Acknowledgements}

A. L-C. received a Ph.D.grant from FONDECYT, Peru. We thank Dr. Vincent Faivre (Institut Galien Paris-Saclay) for useful discussions.

This work did not receive any specific grant from funding agencies in the public, commercial or not-for-profit sectors for running costs. 


\section{REFERENCES}

Aigner, M., \& Lass-Flörl, C. (2020). Encochleated Amphotericin B: is the oral availability of amphotericin B finally reached? Journal of Fungi, 6(2), 66.

https://doi.org/10.3390/jof6020066

Acevedo, R., Pérez, O., Zayas, C., Pérez, J. L., Callicó, A., Cedré, B., García, L., Mckee, D., Mullen, A. B., \& Ferro, V. A. (2012). Cochleates derived from Vibrio cholerae O1 proteoliposomes: the impact of structure transformation on mucosal immunisation. PLoS ONE, 7(10), e46461. https://doi.org/10.1371/journal.pone.0046461

Agrawal, U., Sharma, R., Gupta, M., \& Vyas, S. P. (2014). Is nanotechnology a boon for oral drug delivery? Drug Discovery Today, 19(10), 1530-1546.

https://doi.org/10.1016/j.drudis.2014.04.011

Asprea, M., Tatini, F., Piazzini, V., Rossi, F., Bergonzi, M. C., \& Bilia, A. R. (2019). Stable, monodisperse, and highly cell-permeating nanocochleates from natural soy lecithin liposomes. Pharmaceutics, 11(1), 34. https://doi.org/10.3390/pharmaceutics11010034

Beugin, S., Grabielle-Madelmont, C., Paternostre, M., Ollivon, M., \& Lesieur, S. (1995). Phosphatidylcholine vesicle solubilization by glucosidic non-ionic surfactants: A turbidity and X-ray diffraction study. In J. Appell \& G. Porte (Eds.), Trends in Colloid and Interface Science IX (Vol. 98, pp. 206-211). Steinkopff. https://doi.org/10.1007/BFb0115239

Bhattacharjee S. (2016) DLS and zeta potential - What they are and what they are not? Journal of Controlled Release, 235, 337-351. doi: 10.1016/j.jconrel.2016.06.017.

Bhosale, R. R., Ghodake, P. P., Nandkumar, A., \& Ghadge, A. A. (2013). Nanocochleates: A novel carrier for drug transfer. Journal of Scientific and Innovative Research, 2 (5): 964-969. Available online at: www.jsirjournal.com

Bozó, T., Wacha, A., Mihály, J., Bóta, A., \& Kellermayer, M. S. Z. (2017). Dispersion and stabilization of cochleate nanoparticles. European Journal of Pharmaceutics and Biopharmaceutics, 117, 270-275. https://doi.org/10.1016/j.ejpb.2017.04.030

Chemin, C., Péan, J.M., Bourgaux, C., Pabst, G., Wüthrich, P., Couvreur, P. \& Ollivon, M. (2009). Supramolecular organization of S12363-liposomes prepared with two different remote loading processes. Biochim Biophys Acta. 1788(5), 926-935. doi:

10.1016/j.bbamem.2008.11.017.

Chiu, M. H., \& Prenner, E. J. (2011). Differential scanning calorimetry: An invaluable tool for a detailed thermodynamic characterization of macromolecules and their interactions. Journal of Pharmacy and Bioallied Sciences, 3(1), 39-59. https://doi.org/10.4103/09757406.76463

Choi, S., Ware, W., Lauterbach, S. R., \& Phillips, W. M. (1991). Infrared spectroscopic studies on the phosphatidylserine bilayer interacting with calcium ion: effect of cholesterol. Biochemistry, 30(35), 8563-8568. https://doi.org/10.1021/bi00099a011

Düzgüneş, N., \& Ohki, S. (1977). Calcium-induced interaction of phospholipid vesicles and bilayer lipid membranes. Biochimica et Biophysica Acta (BBA) - Biomembranes, 467(3), 301308. https://doi.org/10.1016/0005-2736(77)90307-8 
Filipe, V., Hawe, A. \& Jiskoot, W. (2010). Critical evaluation of nanoparticle tracking analysis (NTA) by NanoSight for the measurement of nanoparticles and protein aggregates. Pharm Res 27, 796-810. https://doi.org/10.1007/s11095-010-0073-2

Flach, C. R., \& Mendelsohn, R. (1993). A new infrared spectroscopoic marker for cochleate phases in phosphatidylserine-containing model membranes. Biophysical Journal, 64(4), 1113-1121. https://doi.org/10.1016/S0006-3495(93)81477-2

Gao, C., Kewalramani, S., Valencia, D. M., Li, H., McCourt, J. M., Olvera de la Cruz, M., \& Bedzyk, M. J. (2019). Electrostatic shape control of a charged molecular membrane from ribbon to scroll. Proceedings of the National Academy of Sciences of the United States of America, 116(44), 22030-22036. https://doi.org/10.1073/pnas.1913632116

Gibson, B., Duffy, A. M., Fogerite, S. G., Krause-Elsmore, S., Lu, R., Shang, G., Chen, Z.W., Mannino, R. J., Bouchier-Hayes, D. J., \& Harmey, J. H. (2004). A novel gene delivery system for mammalian cells. Anticancer Research, 24, 483-488.

Gould-Fogerite, S., \& Mannino, R. J. (1997). Protein- or peptide-cochleate vaccines and methods of immunizing using the same. United States Patent No. US5643574A. https://patents.google.com/patent/US5643574A/en

Harkare, B., Kulkarni, A., Aloorkar, N., Suryawanshi, J., Wazarkar, A., \& Osmani, R. (2013). Nanocochleate: a new cornucopia in oral drug delivery. International Journal of Innovations in Pharmaceutical Sciences, 2, 1-9.

Harris, J. R., Lewis, R. J., Baik, C., Pokrajac, L., Billington, S. J., \& Palmer, M. (2011). Cholesterol microcrystals and cochleate cylinders: Attachment of pyolysin oligomers and domain 4. Journal of Structural Biology, 173(1), 38-45.

https://doi.org/10.1016/j.jsb.2010.07.010

He, B. B. (2018). Two-dimensional X-ray Diffraction. John Wiley \& Sons. doi:10.1002/9781119356080

Hui, S. W., Boni, L. T., Stewart, T. P., \& Isac, T. (1983). Identification of phosphatidylserine and phosphatidylcholine in calcium-induced phase separated domains. Biochemistry, 22(14), 3511-3516. https://doi.org/10.1021/bi00283a032

Jin, T., Mannino, R., \& Zarif, L. (2001). Novel hydrogel isolated cochleate formulations, process of preparation and their use for the delivery of biologically relevant molecules. US Patent US6153217A https://patents.google.com/patent/US6153217A/en.

Kalepu, S., Manthina, M., \& Padavala, V. (2013). Oral lipid-based drug delivery systems - an overview. Acta Pharmaceutica Sinica B, 3(6), 361-372.

https://doi.org/10.1016/j.apsb.2013.10.001

Kay, J. G., \& Grinstein, S. (2011). Sensing phosphatidylserine in cellular membranes. Sensors (Basel, Switzerland), 11(2), 1744-1755. https://doi.org/10.3390/s110201744

Koomer, A. (2009). Formulation of NPDDS for gene delivery. In "Drug Delivery Nanoparticles Formulation and Characterization" (ed. Pathak, Y. \& Thassu, D.) CRC Press, pp 51-56. 
Landge, A., Pawar, A., Shaikh K. (2013). Investigation of cochleates as carriers for topical drug delivery. International Journal of Pharmacy and Pharmaceutical Sciences, 5(2), 314320 .

Li, C., Wang, J., Wang, Y., Gao, H., Wei, G., Huang, Y., Yu, H., Gan, Y., Wang, Y., Mei, L., Chen, H., Hu, H., Zhang, Z., \& Jin, Y. (2019). Recent progress in drug delivery. Acta Pharmaceutica Sinica B, 9(6), 1145-1162. https://doi.org/10.1016/j.apsb.2019.08.003

Li, J., Wang, X., Zhang, T., Wang, C., Huang, Z., Luo, X., \& Deng, Y. (2015). A review on phospholipids and their main applications in drug delivery systems. Asian Journal of Pharmaceutical Sciences, 10(2), 81-98. https://doi.org/10.1016/j.ajps.2014.09.004

Lipa-Castro, A., Nicolas, V., Angelova, A., Mekhloufi, G., Prost, B., Chéron, M., Faivre, V., \& Barratt, G. (2021). Cochleate formulations of Amphotericin B designed for oral administration using a naturally occurring phospholipid. International Journal of Pharmaceutics, 603, 120688. https://doi.org/10.1016/j.ijpharm.2021.120688.

Liu, M., Zhong, X., \& Yang, Z. (2017). Chitosan functionalized nanocochleates for enhanced oral absorption of cyclosporine A. Scientific Reports, 7(1), 1-10.

https://doi.org/10.1038/srep41322

Livne, L., Epand, R. F., Papahadjopoulos-Sternberg, B., Epand, R. M., \& Mor, A. (2010). OAK-based cochleates as a novel approach to overcome multidrug resistance in bacteria. The FASEB Journal, 24(12), 5092-5101. https://doi.org/10.1096/fj.10-167809

Mannino, R. J. (2016). Lipid-crystal nanoparticles: formulation and delivery of oligonucleotides.

https://d1io3yog0oux5.cloudfront.net/_e3f59a1dab64bfddcc4617df443c6e61/matinasbiophar ma/db/284/2351/pdf/CHI+Oligonucleotide+Poster+04052016.pdf Accessed 27 May 2021.

Mannino, R. J., Gould-Fogerite, S., Krause-Elsmore, S. L., Delmarre, D., \& Lu, R. (2005). Novel encochleation methods, cochleates and methods of use. https://patents.google.com/patent/WO2004091578A8/en.

Manrique-Moreno, M., Heinbockel, L., Suwalsky, M., Garidel, P., \& Brandenburg, K. (2016). Biophysical study of the non-steroidal anti-inflammatory drugs (NSAID) ibuprofen, naproxen and diclofenac with phosphatidylserine bilayer membranes. Biochimica et Biophysica Acta (BBA) - Biomembranes, 1858(9), 2123-2131. https://doi.org/10.1016/j.bbamem.2016.06.009

McCarthy, N. L. C., \& Brooks, N. J. (2016). Using high pressure to modulate lateral structuring in model lipid membranes. In A. Iglič, C. V. Kulkarni, \& M. Rappolt (Eds.), Advances in Biomembranes and Lipid Self-Assembly (Vol. 24, pp. 75-89). Academic Press. https://doi.org/10.1016/bs.abl.2016.04.004

Miclea, R. D., Varma, P. R., Peng, A., \& Balu-Iyer, S. V. (2007). Development and characterization of lipidic cochleate containing recombinant factor VIII. Biochimica et Biophysica Acta, 1768(11), 2890-2898. https://doi.org/10.1016/j.bbamem.2007.08.001

Mourdikoudis, S., Pallares, R. M., \& Thanh, N. T. K. (2018). Characterization techniques for nanoparticles: Comparison and complementarity upon studying nanoparticle properties. Nanoscale, 10(27), 12871-12934. https://doi.org/10.1039/C8NR02278J 
Nagarsekar, K., Ashtikar, M., Steiniger, F., Thamm, J., Schacher, F., \& Fahr, A. (2016). Understanding cochleate formation: Insights into structural development. Soft Matter, 12(16), 3797-3809. https://doi.org/10.1039/C5SM01469G

Nagarsekar, K., Ashtikar, M., Steiniger, F., Thamm, J., Schacher, F. H., \& Fahr, A. (2017). Micro-spherical cochleate composites: Method development for monodispersed cochleate system. Journal of Liposome Research, 27(1), 32-40. https://doi.org/10.3109/08982104.2016.1149865

Nagle, J. F., \& Wiener, M. C. (1989). Relations for lipid bilayers. Connection of electron density profiles to other structural quantities. Biophysical Journal, 55(2), 309-313. https://doi.org/10.1016/S0006-3495(89)82806-1

Nir, S., Bentz, J., Wilschut, J., \& Duzgunes, N. (1983). Aggregation and fusion of phospholipid vesicles. Progress in Surface Science, 13(1), 1-124.

https://doi.org/10.1016/0079-6816(83)90010-2

Papahadjopoulos, D., Vail, W.J., Jacobson, K. \& Poste, G. (1975) Cochleate lipid cylinders: formation by fusion of unilamellar lipid vesicles. Biochim Biophys Acta. 394(3):483-491. doi: 10.1016/0005-2736(75)90299-0.

Papahadjopoulos-Sternberg, B. (2012). Secondary structure formation by bilayer-active peptides studied by freeze-fracture electron microscopy:from disc micelles to cochleate cylinder. Biophysical Journal, 102(3, Supplement 1), 290a.

https://doi.org/10.1016/j.bpj.2011.11.1603

Parasassi, T., De Stasio, G., Ravagnan, G., Rusch, R. M., \& Gratton, E. (1991). Quantitation of lipid phases in phospholipid vesicles by the generalized polarization of Laurdan fluorescence. Biophysical Journal, 60(1), 179-189. doi: 10.1016/S0006-3495(91)82041-0

Patra, J. K., Das, G., Fraceto, L. F., Campos, E. V. R., Rodriguez-Torres, M. del P., AcostaTorres, L. S., Diaz-Torres, L. A., Grillo, R., Swamy, M. K., Sharma, S., Habtemariam, S., \& Shin, H.-S. (2018). Nano based drug delivery systems: Recent developments and future prospects. Journal of Nanobiotechnology, 16(1), 71. https://doi.org/10.1186/s12951-0180392-8

Pawar, A., Bothiraja, C., Shaikh, K., \& Mali, A. (2015). An insight into cochleates, a potential drug delivery system. RSC Advances, 5(99), 81188-81202.

https://doi.org/10.1039/C5RA08550K

Pham, T. T. H., Barratt, G., Michel, J. P., Loiseau, P. M., \& Saint-Pierre-Chazalet, M. (2013). Interactions of antileishmanial drugs with monolayers of lipids used in the development of amphotericin B-miltefosine-loaded nanocochleates. Colloids and Surfaces B: Biointerfaces, 106, 224-233. https://doi.org/10.1016/j.colsurfb.2013.01.041

Pham, T. T. H., Gueutin, C., Cheron, M., Abreu, S., Chaminade, P., Loiseau, P. M., \& Barratt, G. (2014). Development of antileishmanial lipid nanocomplexes. Biochimie, 107, 143-153. https://doi.org/10.1016/j.biochi.2014.06.007

Portis, A., Newton, C., Pangborn, W., \& Papahadjopoulos, D. (1979). Studies on the mechanism of membrane fusion: Evidence for an intermembrane calcium $\left({ }^{2+}\right)$ ion- 
phospholipid complex, synergism with magnesium $\left({ }^{2+}\right)$ ion, and inhibition by spectrin. Biochemistry, 18(5), 780-790. https://doi.org/10.1021/bi00572a007

Rachkauskas, R. (2014). Structural and functional effects of non-steroidal anti-inflammatory drugs rofecixib and valdecoxib on DSPC model membranes. M.Sc. thesis, Middle East Technical University. https://open.metu.edu.tr/bitstream/handle/11511/23844/index.pdf

Ramani, K., \& Balasubramanian, S. V. (2003). Fluorescence properties of Laurdan in cochleate phases. Biochimica et Biophysica Acta (BBA) - Biomembranes, 1618(1), 67-78. https://doi.org/10.1016/j.bbamem.2003.10.009

Ramasamy, T., Khandasamy, U., Hinabindhu, R., \& Kona, K. (2009). Nanocochleate - a new drug delivery dystem. FABAD J. Pharm. Sci., 34, 91-101

Rao, R., Squillante, E., \& Kim, K. H. (2007). Lipid-based cochleates: A promising formulation platform for oral and parenteral delivery of therapeutic agents. Critical Reviews in Therapeutic Drug Carrier Systems, 24(1), 41-61. https://doi.org/10.1615/critrevtherdrugcarriersyst.v24.i1.20

Rongen, R. (2016). Delivery platform - encochleated drug formulations: enhancing efficacy, minimizing toxicity. Drug Development \& Delivery, 16 (6), p8.

Roux, M. \& Bloom, M. (1990). $\mathrm{Ca}^{2+}, \mathrm{Mg}^{2+}, \mathrm{Li}^{+}, \mathrm{Na}^{+}$, and $\mathrm{K}^{+}$distributions in the headgroup region of binary membranes of phosphatidylcholine and phosphatidylserine as seen by deuterium NMR. Biochemistry 29, 7077-7089. doi: 10.1021/bi00482a019.

Roux, M. \& Bloom, M. (1991) Calcium binding by phosphatidylserine headgroups. Deuterium NMR study. Biophys J., 60(1), 38-44. doi: 10.1016/S0006-3495(91)82028-8.

Sankar, R., \& Reddy Y, D. (2010). Nanocochleate-A new approch in lipid drug delivery. International Journal of Pharmacy and Pharmaceutical Sciences, 2, 220-223.

Santangelo, R., Paderu, P., Delmas, G., Chen, Z.-W., Mannino, R., Zarif, L., \& Perlin, D. S. (2000). Efficacy of oral cochleate-amphotericin B in a mouse model of systemic candidiasis. Antimicrobial Agents and Chemotherapy, 44(9), 2356-2360.

https://doi.org/10.1128/AAC.44.9.2356-2360.

Sarig, H., Ohana, D., Epand, R. F., Mor, A., \& Epand, R. M. (2011). Functional studies of cochleate assemblies of an oligo-acyl-lysyl with lipid mixtures for combating bacterial multidrug resistance. The FASEB Journal, 25(10), 3336-3343. https://doi.org/10.1096/fj.11183764

Sharma, M., Sharma, R., \& Jain, D. K. (2016). Nanotechnology based bpproaches for enhancing oral bioavailability of poorly water soluble antihypertensive drugs. Scientifica, 2016, 8525679. https://doi.org/10.1155/2016/8525679

Silvius, J. R., \& Gagne, J. (1984). Calcium-induced fusion and lateral phase separations in phosphatidylcholine-phosphatidylserine vesicles. Correlation by calorimetric and fusion measurements. Biochemistry, 23(14), 3241-3247. https://doi.org/10.1021/bi00309a019 
Syed, U. M., Woo, A. F., Plakogiannis, F., Jin, T., \& Zhu, H. (2008). Cochleates bridged by drug molecules. International Journal of Pharmaceutics, 363(1-2), 118-125.

https://doi.org/10.1016/j.ijpharm.2008.06.026

Tilcock, C.P., Bally, M.B., Farren, S.B., Cullis, P.R. \& Gruner, S.M. (1984) Cation-dependent segregation phenomena and phase behavior in model membrane systems containing phosphatidylserine: influence of cholesterol and acyl chain composition. Biochemistry, 23(12), 2696-2703. doi: 10.1021/bi00307a025.

Vijeta, P., Vivek, M., Panwar, A.S., Darwhekar, G.N. \& Jain, D.K. (2011). Nanocochleate as drug delivery vehicle. International Journal of Pharmacy and Biological Sciences, 1(1), 3138 .

Wang, N., Wang, T., Zhang, M., Chen, R., \& Deng, Y. (2014). Using procedure of emulsification-lyophilization to form lipid A-incorporating cochleates as an effective oral mucosal vaccine adjuvant-delivery system (VADS). International Journal of Pharmaceutics, 468(1), 39-49. https://doi.org/10.1016/j.ijpharm.2014.04.002

Wilschut, J., Duzgunes, N., Fraley, R., \& Papahadjopoulos, D. (1980). Studies on the mechanism of membrane fusion: Kinetics of calcium ion induced fusion of phosphatidylserine vesicles followed by a new assay for mixing of aqueous vesicle contents. Biochemistry, 19(26), 6011-6021. https://doi.org/10.1021/bi00567a011

Yadav, A., \& Chaudhary, S. (2016). Formulation development and characterization of nanocochleates for the improvement of permeability of drug. Journal of Advanced Pharmacy Education and Research 6(3), 14-21. Available on-line at www.japer.in

Zarif, L., Graybill, J. R., Perlin, D., Najvar, L., Bocanegra, R., \& Mannino, R. J. (2000). Antifungal activity of amphotericin B cochleates against Candida albicans infection in a mouse model. Antimicrobial Agents and Chemotherapy, 44(6), 1463-1469.

https://doi.org/10.1128/AAC.44.6.1463-1469.2000

Zarif, Leila, Graybill, J. R., Perlin, D., \& Mannino, R. J. (2000). Cochleates: New LipidBased Drug Delivery System. Journal of Liposome Research, 10(4), 523-538. https://doi.org/10.3109/08982100009031116

Zarif, L. (2002). Elongated supramolecular assemblies in drug delivery. Journal of Controlled Release, 81(1-2), 7-23. https://doi.org/10.1016/s0168-3659(02)00010-x

Zarif, L. (2005). Drug delivery by lipid cochleates. In Methods in Enzymology (Vol. 391, pp. 314-329). Academic Press. https://doi.org/10.1016/S0076-6879(05)91018-5

Zarif, L, Jin, T., Segarra, I., \& Mannino, R. J. (2003). Hydrogel-isolated cochleate formulations, process of preparation and their use for the delivery of biologically relevant molecules (United States Patent No. US6592894B1).

https://patents.google.com/patent/US6592894B1/en

Zarif, L. \& Mannino, R. J. (2002). Cochleates. In N. A. Habib (Ed.), Cancer Gene Therapy: Past Achievements and Future Challenges (pp. 83-93). Springer US. https://doi.org/10.1007/0-306-46817-49. 
Zerkoune, L., Lesieur, S., Putaux, J.-L., Choisnard, L., Gèze, A., Wouessidjewe, D., Angelov, B., Vebert-Nardin, C., Doutch, J., \& Angelova, A. (2016). Mesoporous self-assembled nanoparticles of biotransesterified cyclodextrins and nonlamellar lipids as carriers of waterinsoluble substances. Soft Matter, 12(36), 7539-7550. https://doi.org/10.1039/C6SM00661B 


\begin{tabular}{|c|c|c|c|}
\hline Drug Name & Activity & BCS Class & Reference \\
\hline 5-Fluorouracil & Anticancer & III & Pawar et al., 2015 \\
\hline Acetaminophen & NSAID & III & Mannino et al., 2014 \\
\hline Acyclovir & Antiviral & III & Pawar et al., 2015 \\
\hline Amiloride & CVS & III & Pawar et al., 2015 \\
\hline Amitriptyline & CNS & I & Pawar et al., 2015 \\
\hline Amoxicillin & Antibiotic & III & Pawar et al., 2015 \\
\hline Amphotericin B & Antifungal & IV & Mannino et al., 2014 \\
\hline Andrographolide & Anti-inflammatory & IV & Asprea et al., 2019 \\
\hline ApoA1 & Apoliprotein & N/A & Ramasamy et al., 2009 \\
\hline Aspirin & NSAID & $\mathrm{I}$ & Ramasamy et al., 2009 \\
\hline Atenolol & CVS & III & Pawar et al., 2015 \\
\hline Atropine & Antispasmodic & III & Pawar et al., 2015 \\
\hline Benzodiazepines & CNS & II & Pawar et al., 2015 \\
\hline Bidisomide & CVS & III & Pawar et al., 2015 \\
\hline Bisphosphonates & Antiosteoporosis & III & Pawar et al., 2015 \\
\hline Buspirone & CNS & $\mathrm{I}$ & Pawar et al., 2015 \\
\hline Capecitabine & Anticancer & I & Pawar et al., 2015 \\
\hline Captopril & CVS & I & Pawar et al., 2015 \\
\hline Caspofungin & Antifungal & III & Mannino et al., 2014 \\
\hline Cefazolin & Antibiotic & III & Pawar et al., 2015 \\
\hline Celecoxib & NSAID & II & Pawar et al., 2015 \\
\hline Cetirizine & Antihistamine & III & Pawar et al., 2015 \\
\hline Chlorothiazide & Diuretic & IV & Pawar et al., 2015 \\
\hline Chlorpromazine & CNS & II & Pawar et al., 2015 \\
\hline Chlorthalidone & Antihypertensive & IV & Pawar et al., 2015 \\
\hline Cimetidine & Antihistamine & III & Pawar et al., 2015 \\
\hline Ciprofloxacin & Antibiotic & III & Pawar et al., 2015 \\
\hline Cisplatin & Anticancer & II & Pawar et al., 2015 \\
\hline Clofazimine & Antibiotic & II & Ramasamy et al., 2009 \\
\hline Cloxacillin & Antibiotic & III & Pawar et al., 2015 \\
\hline Clozapine & CNS & II & Pawar et al., 2015 \\
\hline Colistin & Antibiotic & IV & Pawar et al., 2015 \\
\hline Cyclosporine A & Immunosuppression & II & Liu et al., 2017 \\
\hline Diclofenac & NSAID & II & Pawar et al., 2015 \\
\hline Dicloxacillin & Antibiotic & III & Pawar et al., 2015 \\
\hline Diltiazem & CVS & I & Pawar et al., 2015 \\
\hline DNA & Gene therapy & N/A & Ramasamy et al., 2009 \\
\hline Docetaxel & Anticancer & IV & Pawar et al., 2015 \\
\hline Doxorubicin & Anticancer & II & Pawar et al., 2015 \\
\hline Encainide & CVS & III & Pawar et al., 2015 \\
\hline Erythromycin & Antibiotic & III & Pawar et al., 2015 \\
\hline Etoposide & Anticancer & IV & Pawar et al., 2015 \\
\hline Factor VIII & Blood clotting & N/A & Miclea et al., 2007 \\
\hline Famotidine & Anti-ulcer & III & Pawar et al., 2015 \\
\hline Fludarabine & Anticancer & II & Pawar et al., 2015 \\
\hline Fluoxetine & CNS & I & Pawar et al., 2015 \\
\hline Furosemide & Diuretic & IV & Pawar et al., 2015 \\
\hline Gemcitabine & Anticancer & III & Pawar et al., 2015 \\
\hline Haloperidol & CNS & II & Pawar et al., 2015 \\
\hline Hydralazine & CVS & III & Pawar et al., 2015 \\
\hline
\end{tabular}




\begin{tabular}{|l|l|l|l|}
\hline Hydrochlorothiazide & Diuretic & IV & Pawar et al., 2015 \\
\hline Ibuprofen & NSAID & II & Ramasamy et al., 2009 \\
\hline Indomethacin & NSAID & II & Pawar et al., 2015 \\
\hline Irinotecan & Anticancer & II & Pawar et al., 2015 \\
\hline Ketoconazole & Antibiotic & II & Shaikh et al., 2013 \\
\hline Ketorolac & NSAID & I & Pawar et al., 2015 \\
\hline Maprotiline & CNS & III & Pawar et al., 2015 \\
\hline Meloxicam & NSAID & II & Pawar et al., 2015 \\
\hline Mexiletine & CVS & III & Pawar et al., 2015 \\
\hline Naproxen & NSAID & II & Ramasamy et al., 2009 \\
\hline Neomycin & Antibiotic & IV & Pawar et al., 2015 \\
\hline Paclitaxel & Anticancer & IV & Pawar et al., 2015 \\
\hline Phenylbutazone & NSAID & II & Pawar et al., 2015 \\
\hline Piroxicam & NSAID & II & Pawar et al., 2015 \\
\hline Protein antigens & Vaccines & N/A & Ramasamy et al., 2009 \\
\hline Quinidine & CVS & I & Pawar et al., 2015 \\
\hline Rifampicin & Antibiotic & II & Yadar \& Chaudhary, 2016 \\
\hline Risperidone & CNS & II & Pawar et al., 2015 \\
\hline Streptomycin & Antibiotic & III & Mannino et al., 2014 \\
\hline Sulindac & NSAID & II & Pawar et al., 2015 \\
\hline Tobramycin & Antibiotic & IV & Mannino et al., 2014 \\
\hline Tolmetin & NSAID & II & Pawar et al., 2015 \\
\hline Topotecan & Anticancer & I & Pawar et al., 2015 \\
\hline Valdecoxib & NSAID & II & Pawar et al., 2015 \\
\hline Vancomycin & Antibiotic & IV & Mannino et al., 2014 \\
\hline Verapamil & CVS & II & Pawar et al., 2015 \\
\hline Vinblastine & Anticancer & II & Pawar et al., 2015 \\
\hline Vincristine & Anticancer & III & Pawar et al., 2015 \\
\hline Vinorelbine & II & Pawar et al., 2015 \\
\hline Zolpidem & & Pawar et al., 2015 \\
\hline
\end{tabular}

Table 1. Examples of active molecules reported to have been incorporated into cochleates. NSAIDs: non-steroidal anti-inflammatory drugs, CVS: cardiovascular system, CNS: central nervous system, BCS: biopharmaceutical classification system 


\begin{tabular}{|c|c|c|c|}
\hline Technique & Main information derived & Commentary & Section \\
\hline DLS & $\begin{array}{l}\text { Size, size distribution, } \\
\text { detection of agglomerates }\end{array}$ & $\begin{array}{l}\text { This provides a quick and inexpensive analysis, but the } \\
\text { main limitation is that it assumes that the cochleates are } \\
\text { spherical in shape. }\end{array}$ & 6.1 .1 \\
\hline $\begin{array}{l}\text { Optical } \\
\text { microscopy }\end{array}$ & $\begin{array}{l}\text { Size, shape, detection of } \\
\text { agglomerates }\end{array}$ & $\begin{array}{l}\text { Low-cost method that provides quick and inexpensive } \\
\text { analysis without sample pretreatment; however, it } \\
\text { detects only large cochleates. }\end{array}$ & 6.1 .2 \\
\hline TEM & $\begin{array}{l}\text { Size, shape, detection of } \\
\text { agglomerates }\end{array}$ & $\begin{array}{l}\text { Nanometer range can be resolved. However, sample } \\
\text { pretreatment and sophisticated equipment are required. } \\
\text { Furthermore, it cannot detect large cochleates. }\end{array}$ & 6.1 .2 \\
\hline $\begin{array}{l}\text { AFM, SEM, } \\
\text { Freeze- } \\
\text { fracture TEM }\end{array}$ & $\begin{array}{l}\text { Size, shape, rolled } \\
\text { structure }\end{array}$ & $\begin{array}{l}\text { Three-dimensional images of cochleates can be resolved } \\
\text { at the micrometer range by AFM and at the nanometer } \\
\text { range by SEM and Freeze-fracture TEM. These } \\
\text { methods require sophisticated equipment and } \\
\text { experienced operators }\end{array}$ & 6.1 .2 \\
\hline $\begin{array}{l}\text { Fluorescence } \\
\text { microscopy }\end{array}$ & $\begin{array}{l}\text { Size, shape and } \\
\text { interaction with other } \\
\text { materials }\end{array}$ & $\begin{array}{l}\text { Cheap analysis but samples must be prepared } \\
\text { incorporating a fluorescence substance and is limited } \\
\text { for large cochleates }\end{array}$ & 6.1 .2 \\
\hline Turbidimetry & Aggregate state & $\begin{array}{l}\text { Fast and cheap analysis monitoring intermediate and } \\
\text { final structures. }\end{array}$ & 6.2 .1 \\
\hline Zeta potential & $\begin{array}{c}\text { Surface charge } \\
\text { Aggregation state }\end{array}$ & $\begin{array}{l}\text { Fast and cheap analysis for stability study and } \\
\text { identification of the aggregate state. }\end{array}$ & 6.2 .2 \\
\hline $\begin{array}{l}\text { Laurdan } \\
\text { fluorescence }\end{array}$ & $\begin{array}{l}\text { Hydration level } \\
\text { Aggregation state }\end{array}$ & $\begin{array}{l}\text { Fast and cheap technique useful to evaluate the impact } \\
\text { of the inclusion of different drugs. However, } \\
\text { incorporation of the fluorescent substance Laurdan is } \\
\text { necessary. }\end{array}$ & 6.2 .3 \\
\hline DSC & $\begin{array}{l}\text { Aggregate state } \\
\text { Drug-lipid interactions }\end{array}$ & $\begin{array}{l}\text { Fast analysis that studies phase transition and gives } \\
\text { information about drug-lipid interaction but samples are } \\
\text { subjected to temperature variations. }\end{array}$ & 6.2 .4 \\
\hline $\begin{array}{c}\text { X-ray } \\
\text { diffraction }\end{array}$ & $\begin{array}{c}\text { Aggregate state } \\
\text { Internal Structure } \\
\text { (multilamellar packing) }\end{array}$ & $\begin{array}{l}\text { SAXS and WAXS explore changes in phospholipid } \\
\text { bilayers and acyl chain packing respectively. These } \\
\text { techniques are also useful to identify intermediate } \\
\text { structures accurately and to evaluate the impact of the } \\
\text { inclusion of drugs; however sophisticated equipment is } \\
\text { necessary. }\end{array}$ & 6.3 .1 \\
\hline $\begin{array}{c}\text { FT-IR } \\
\text { spectroscopy }\end{array}$ & $\begin{array}{l}\text { Aggregate state } \\
\text { Internal Structure }\end{array}$ & $\begin{array}{l}\text { Fast and cheap analysis of the phospholipid headgroups, } \\
\text { giving information about dehydration or packing state. } \\
\text { Useful to study the impact of drugs in the internal } \\
\text { structure. }\end{array}$ & 6.3 .2 \\
\hline NMR & Internal structure & $\begin{array}{l}\text { Molecular structure information giving fundamental } \\
\text { information about membrane fusion. Main limitation is } \\
\text { the sophisticated equipment required. }\end{array}$ & 6.3 .3 \\
\hline
\end{tabular}

Table 2: Main experimental techniques used for cochleate characterization 


\section{Figure Captions}

Figure 1. Internal structure of cochleates.

Figure 2. Intermediate structures after the addition of calcium ions that give the cochleates as a final product (adapted from Nagarsekar et al., 2016).

Figure 3. Arrangements of the drugs loaded as cochleates (adapted from Zarif, 2005).

Figure 4. Structure of phospholipids used in obtaining cochleates (adapted from Li et al., 2015).

Figure 5. Schematic of the interaction of cochleate particles when the dehydrated bilayers approach a membrane cell resulting cochleate fusion with cell membrane (reproduced with permission from Lipa-Castro et al. 2021).

Figure 6. SEM image of optimized DOPS cochleate composites obtained from the NanoAssembler ${ }^{\mathrm{TM}}$ microfluidic device (reproduced from Nagarsekar et al., 2017, with permission)

Figure 7. Images of cochleates prepared from didecanoylphosphatidylserine observed by different electron microscopy techniques: (a) freeze-fracture transmission electron microscopy, (b) cryo-scanning electron microscopy, (c) scanning electron microscopy. Scale bars are $250 \mathrm{~nm}$ (reproduced with permission from Nagarsekar et al. 1996).

Figure 8. Structural formula of laurdan.

Figure 9. Normalized excitation and emission spectra of laurdan in SUV corresponding to liquid-crystalline phase (green line), cochleate phase (blue line) and gel phase (red line) (adapted with permission from Ramani \& Balasubramanian, 2003).

Figure 10: Small-angle X-ray scattering (SAXS) patterns of MLV (A) and cochleates (B) formed from soy phosphatidylserine. (Reproduced with permission from Lipa-Castro et al. 2021)

Figure 11: Electron density patterns from cochleates formed from dioleoylphosphatidylserine with and without incorporated amphotericin B. (Lipa, Bourgaux, Legrand, Barratt, unpublished results).

Figure 12: FT-IR attenuated total reflectance spectrum of hydrated film of DMPS (adapted with permission from Manrique-Moreno et al., 2016). 


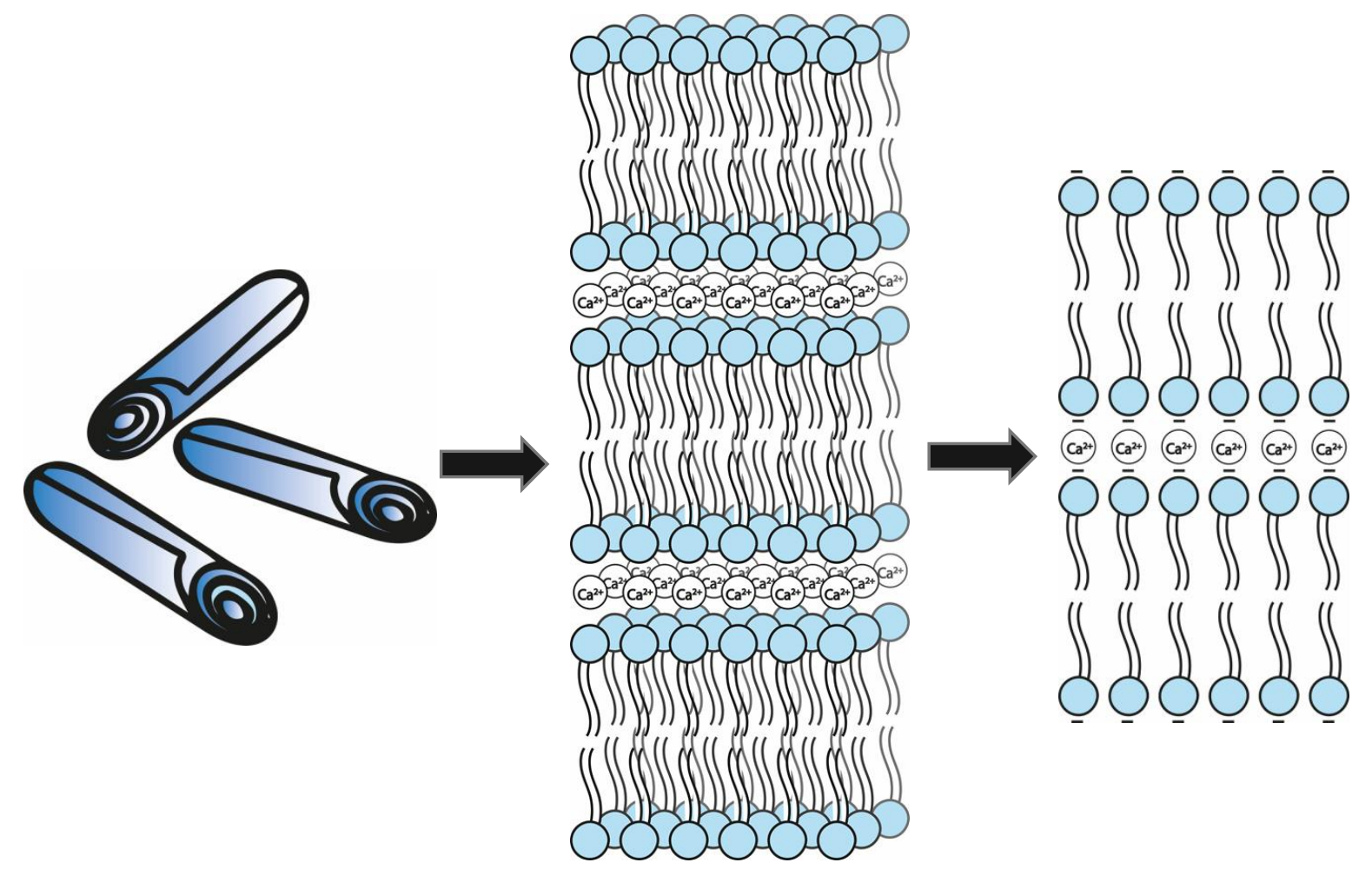

Figure 1 
Figure 2

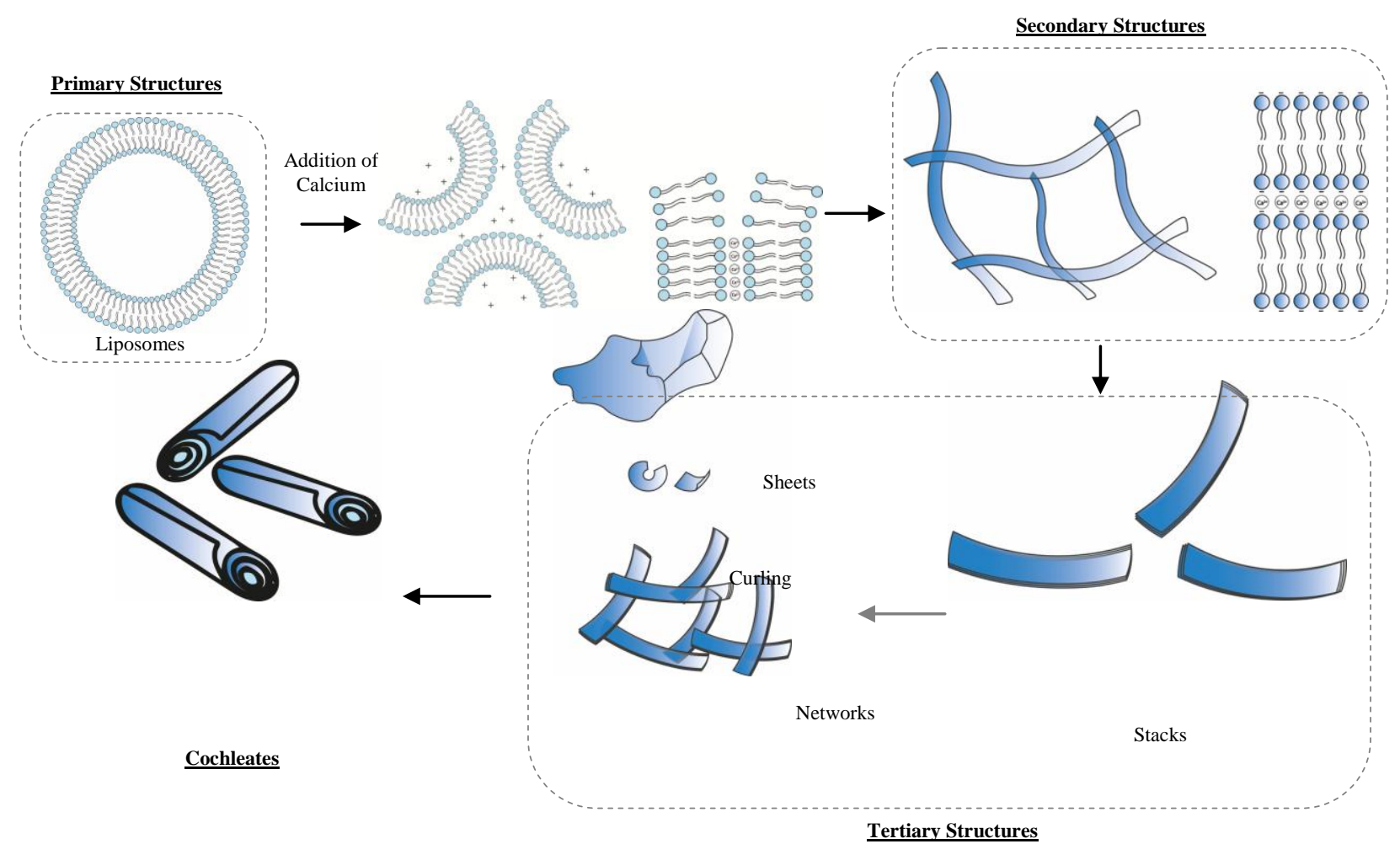


Figure 3
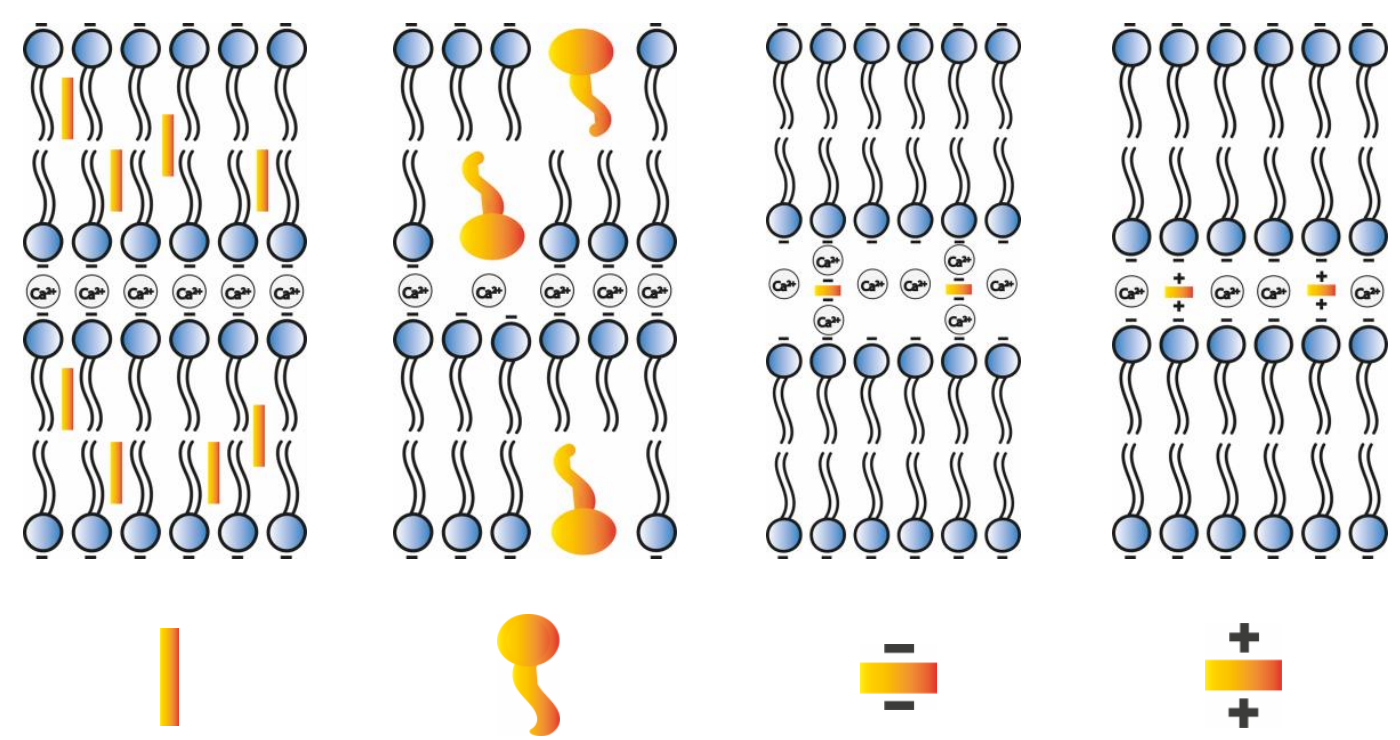

Hydrophobic drug

Amphiphilic drug

Negatively charged drug

Positively charged drug 


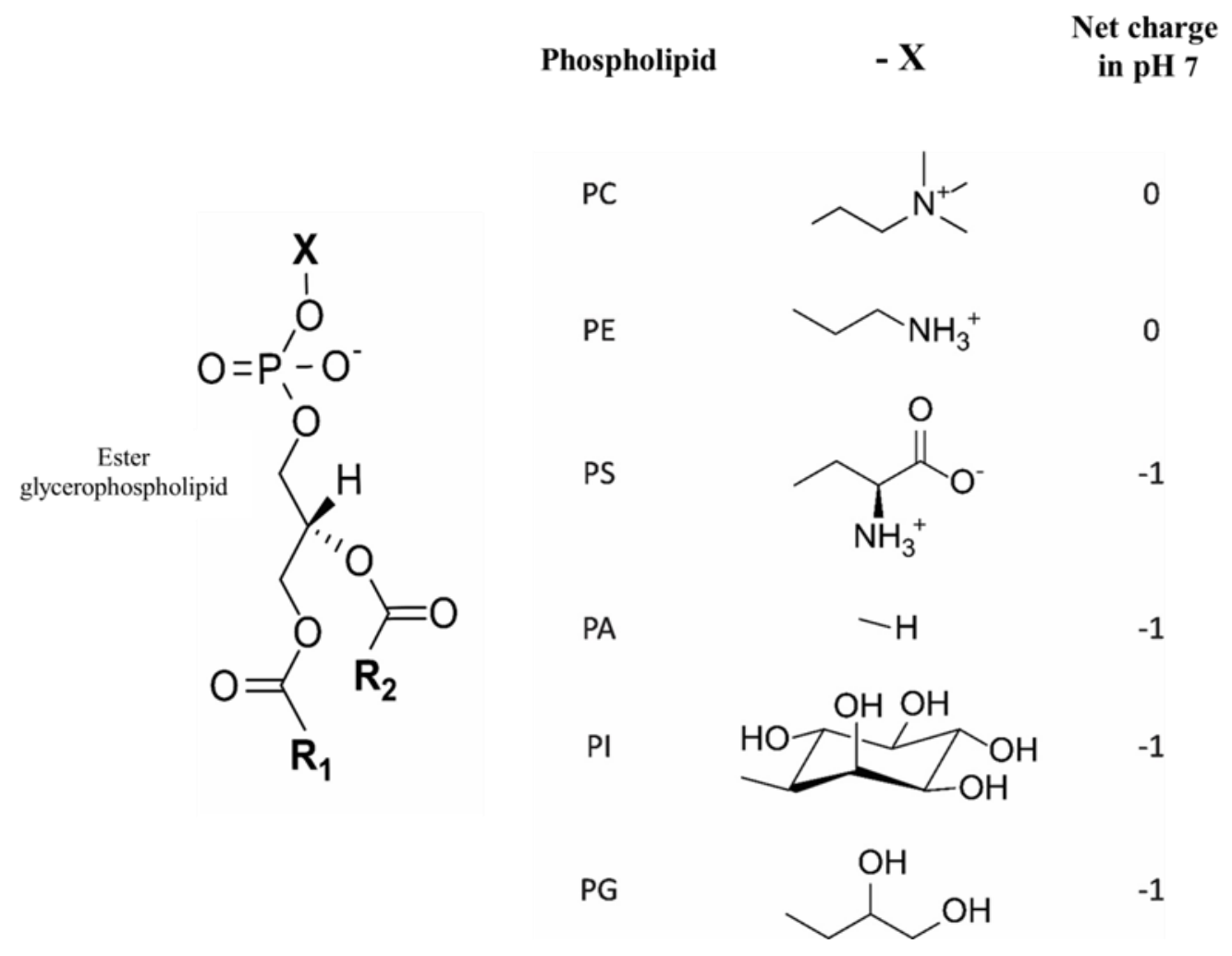

Figure 4 
Figure 5
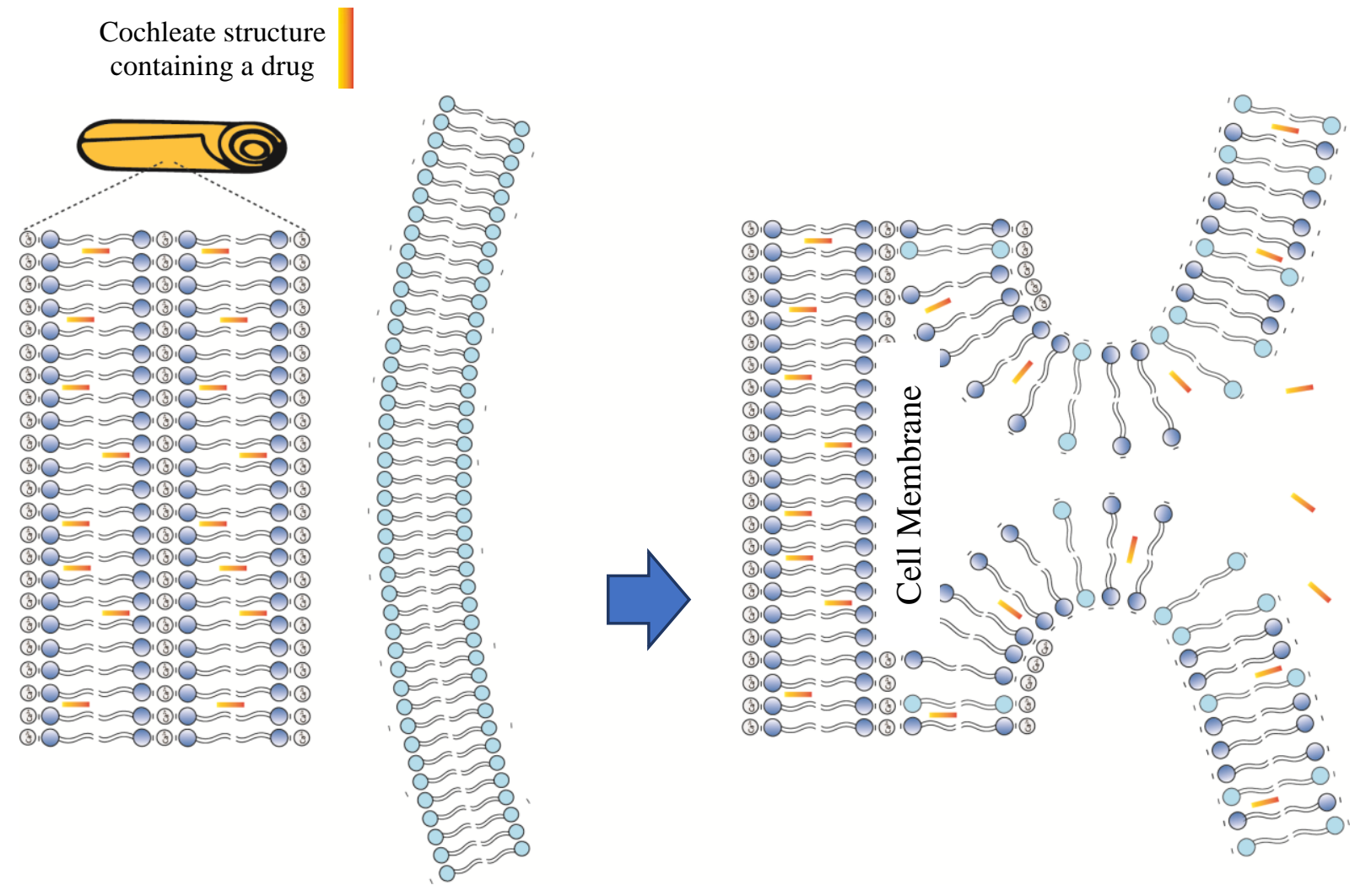
Figure 6

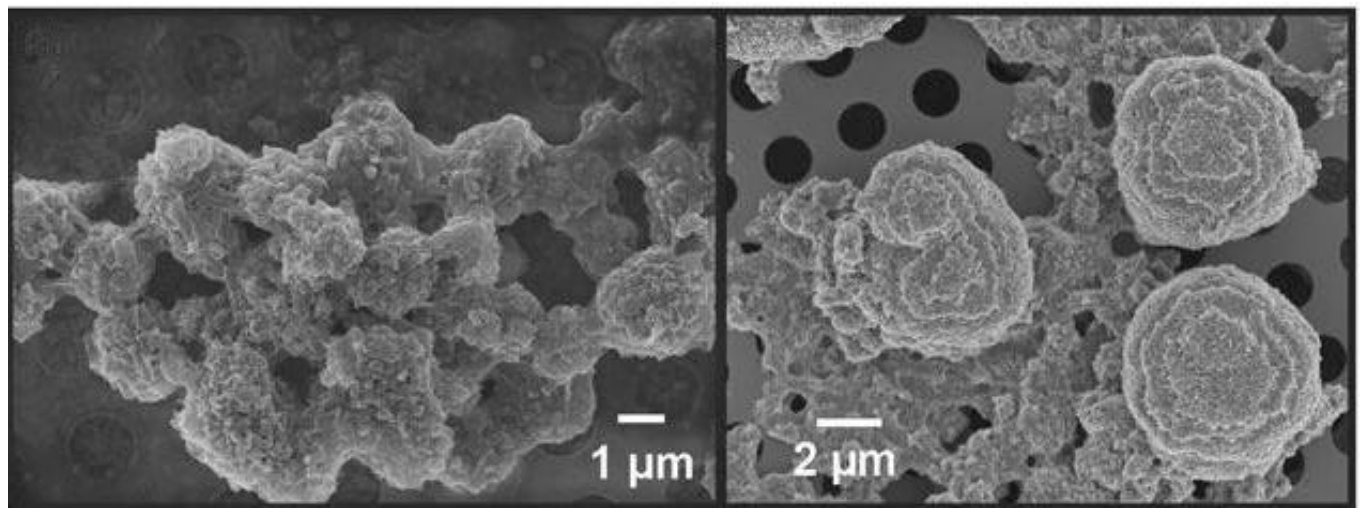

Figure 7

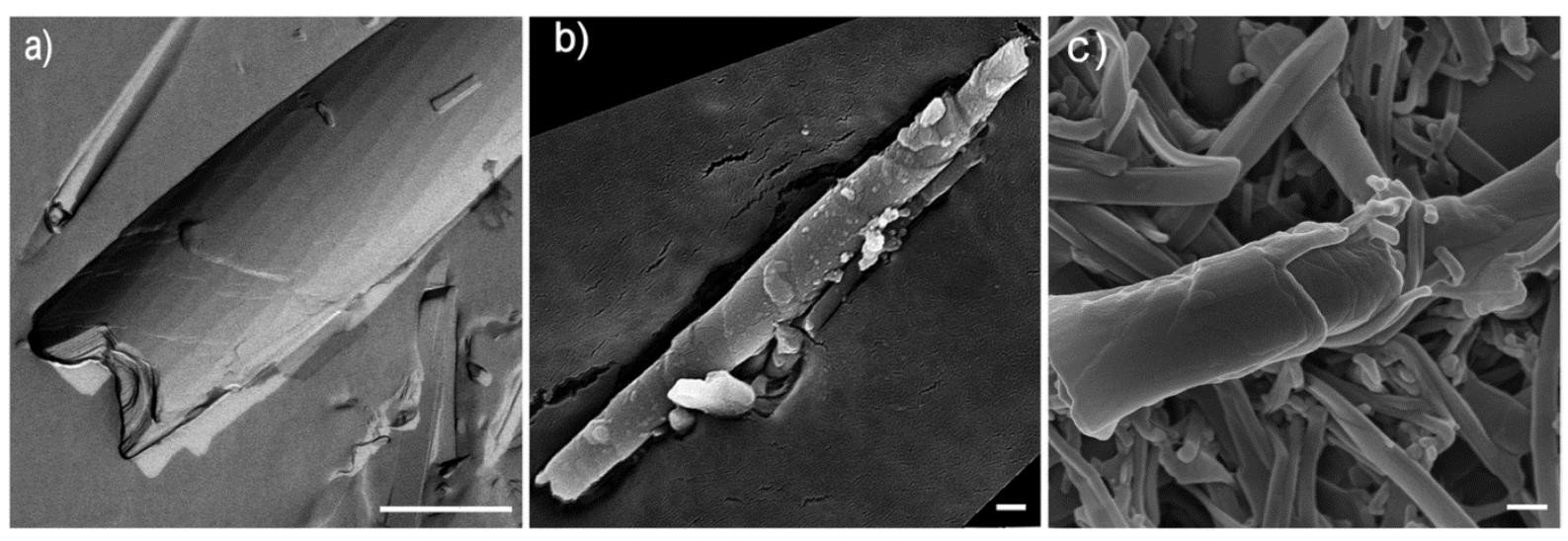


Figure 8

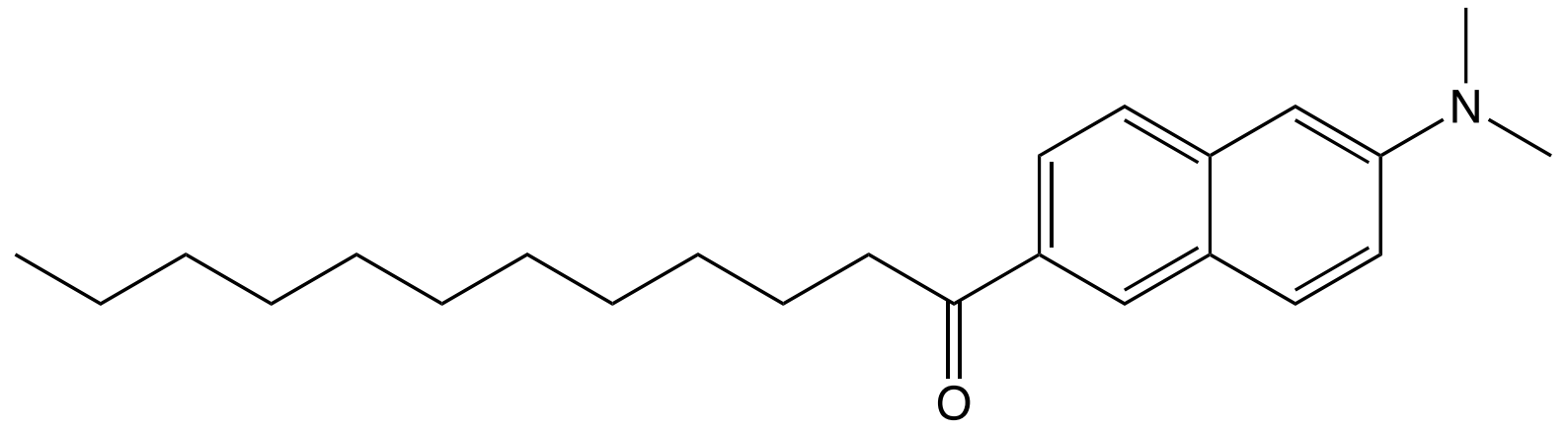

Figure 9

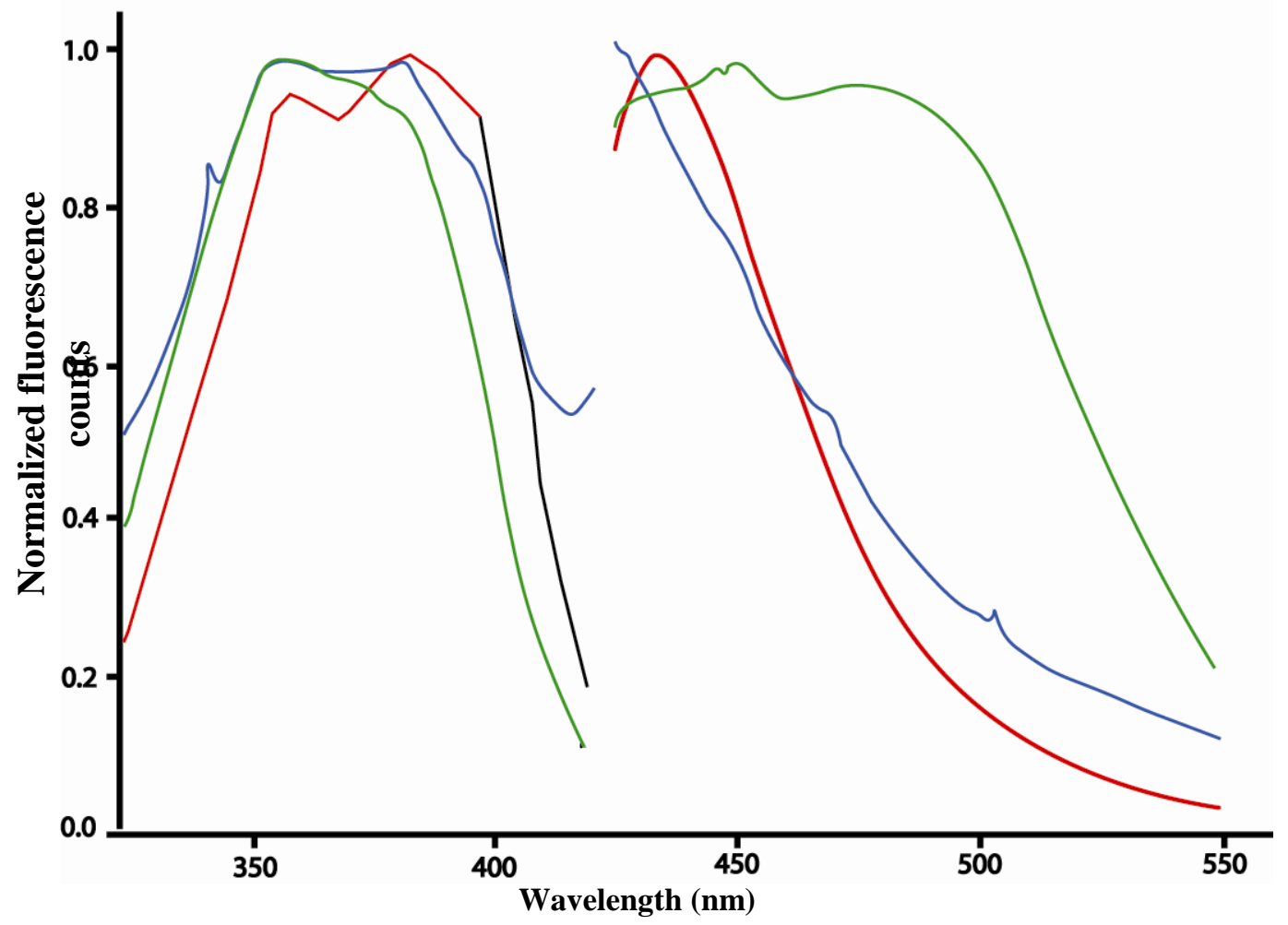


Figure 10

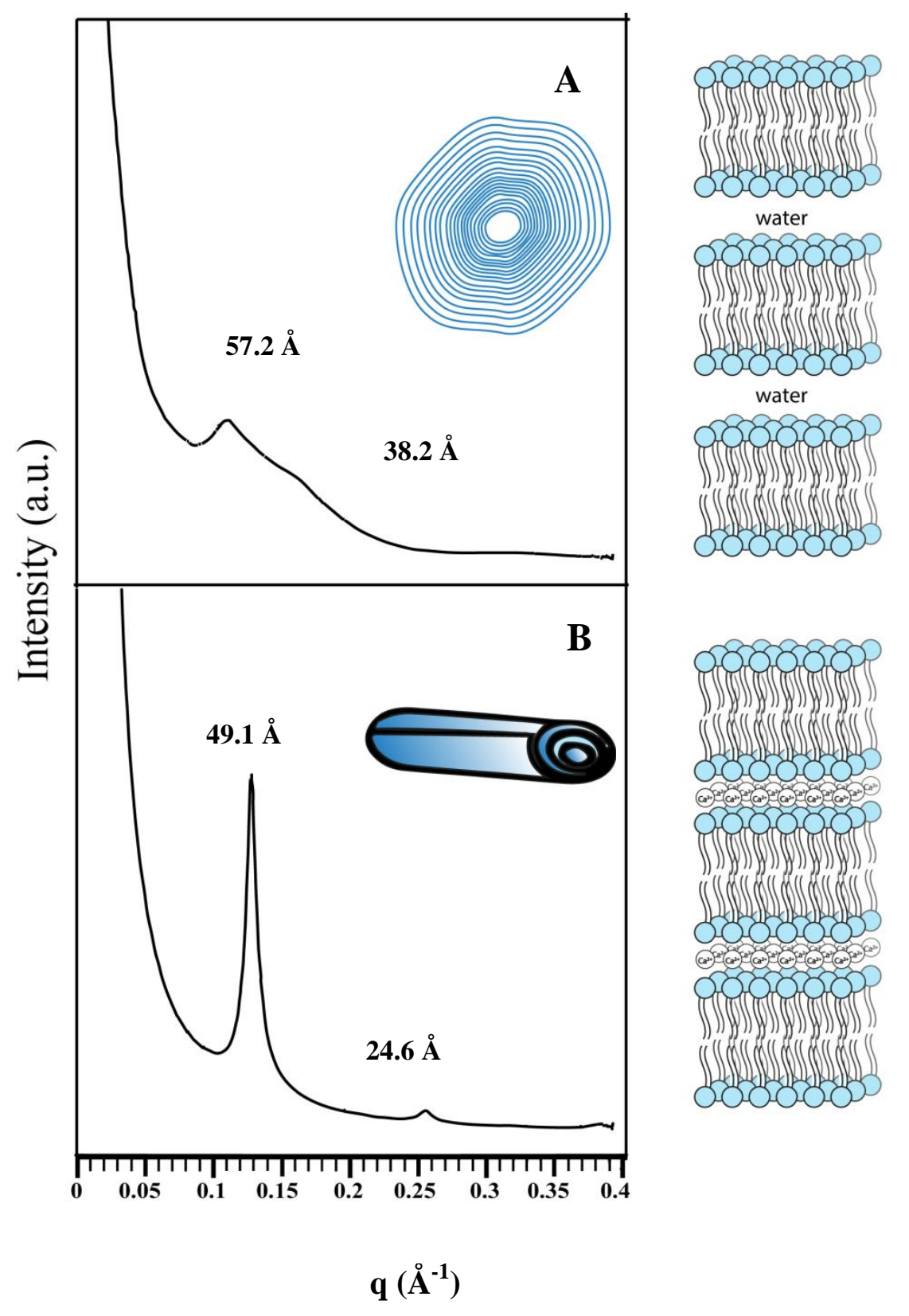


Figure 11
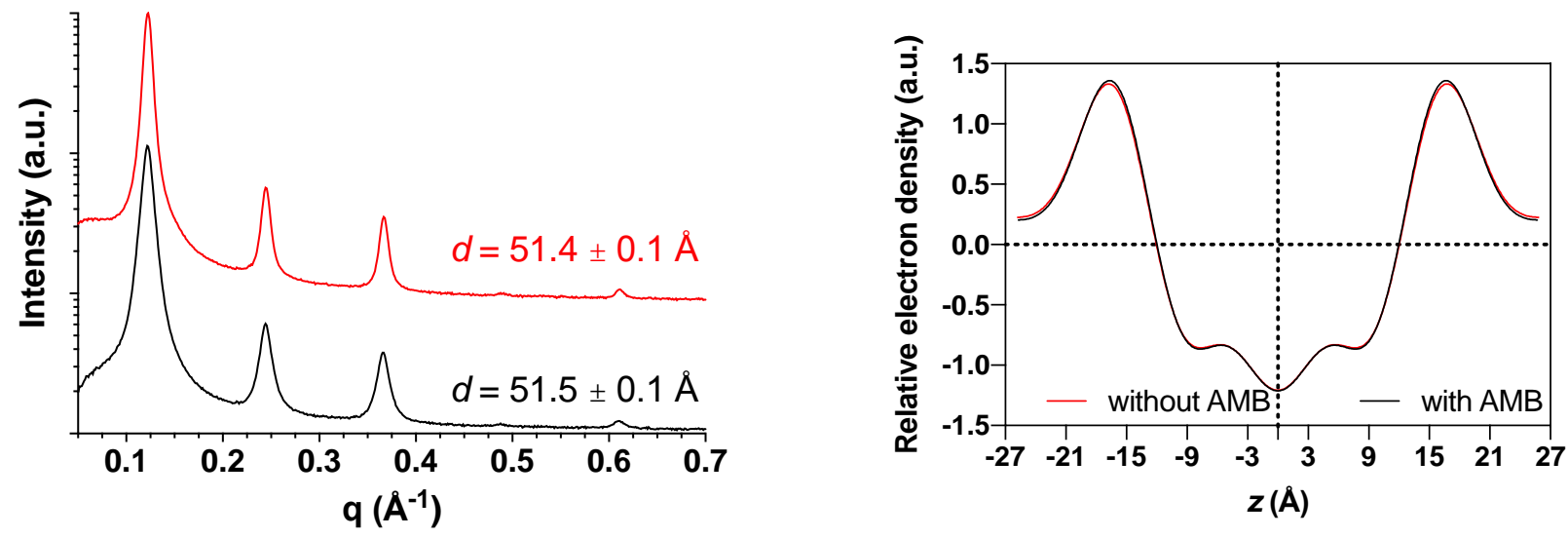

Figure 12

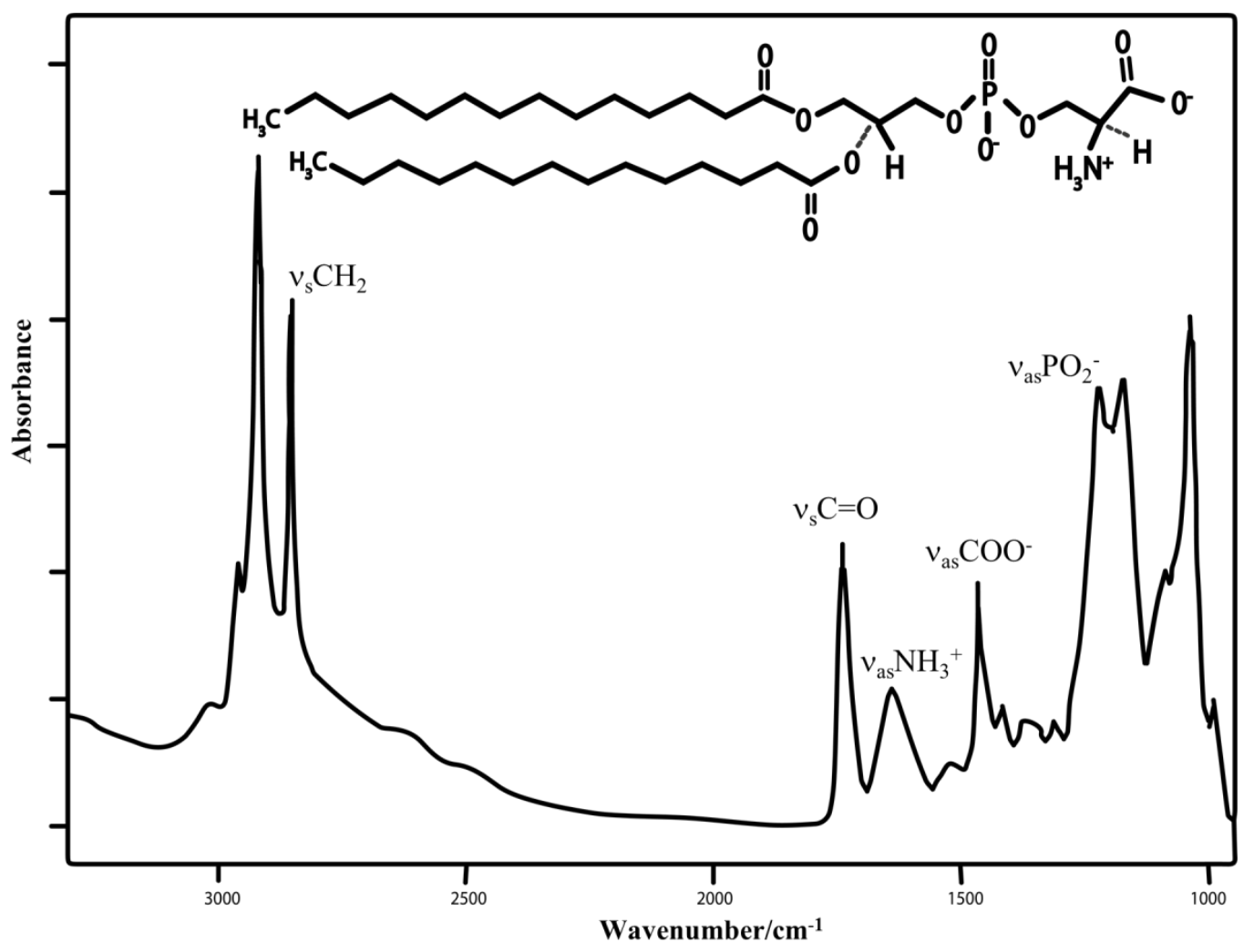

